Review

\title{
Alcohol Withdrawal and Brain Injuries: Beyond Classical Mechanisms
}

\author{
Marianna E. Jung * and Daniel B. Metzger \\ Department of Pharmacology and Neuroscience, University of North Texas Health Science Center at \\ Fort Worth, 3500 Camp Bowie Blvd., Fort Worth, TX 76107-2699, USA; \\ E-Mail: Daniel.Metzger@unthsc.edu (D.B.M.) \\ * Author to whom correspondence should be addressed; E-Mail: Marianna.Jung@unthsc.edu; \\ Tel.: +1-817-735-0132; Fax: +1-817-735-2091.
}

Received: 30 April 2010; in revised form: 15 July 2010 / Accepted: 19 July 2010 /

Published: 20 July 2010

\begin{abstract}
Unmanaged sudden withdrawal from the excessive consumption of alcohol (ethanol) adversely alters neuronal integrity in vulnerable brain regions such as the cerebellum, hippocampus, or cortex. In addition to well known hyperexcitatory neurotransmissions, ethanol withdrawal (EW) provokes the intense generation of reactive oxygen species (ROS) and the activation of stress-responding protein kinases, which are the focus of this review article. EW also inflicts mitochondrial membranes/membrane potential, perturbs redox balance, and suppresses mitochondrial enzymes, all of which impair a fundamental function of mitochondria. Moreover, EW acts as an age-provoking stressor. The vulnerable age to EW stress is not necessarily the oldest age and varies depending upon the target molecule of EW. A major female sex steroid, 17 $\beta$-estradiol (E2), interferes with the EW-induced alteration of oxidative signaling pathways and thereby protects neurons, mitochondria, and behaviors. The current review attempts to provide integrated information at the levels of oxidative signaling mechanisms by which EW provokes brain injuries and E2 protects against it.
\end{abstract}

Keywords: antioxidant; brain aging; 17ß-estradiol; ethanol withdrawal; mitochondria; oxidative stress; protein kinase; protein oxidation 


\section{Ethanol Withdrawal (EW)}

EW refers an abrupt termination of long-term heavy ethanol consumption, the acute syndromes of which range from psychological symptoms to physical signs. Those are anxiety, depression, tremors, rigidity, hyperactivity, convulsion, coma, and even death. These signs often determine whether or not an individual is alcohol dependent. Many alcohol dependent individuals attempt to quit ethanol abuse but distress associated with these syndromes provides motivation to relapse into ethanol abuse [1]. As they repeat the vicious cycle of hazardous drinking and unsuccessful detoxification, the intensity of EW syndromes increases [2]. Clinically, benzodiazepines are the primary available treatments but their side effects such as respiratory inhibition or dependence liability limit their therapeutic usage. As a step towards the development of a better research and therapeutic strategy, we and others have strived to identify the mechanisms by which EW damages the brain.

Numerous studies have documented deleterious effects of ethanol abuse such as liver damage, increased inflammation, cardiac dysfunction and cognitive deficit [3,4]. However, compared to ethanol per se, relatively few studies have reported the effects of EW on the brain. EW stress is initiated by a sudden removal of a neurosuppressant ethanol. Therefore, classical mechanisms underlying EW stimulus involve enhanced excitatory (e.g. glutamate) and suppressed inhibitory (e.g. GABA) neurotransmittal systems [5]. These mechanisms, as well as other neurotransmittal systems such as dopamine and serotonin involved in ethanol/EW effects, were thoroughly reviewed by Fadda and Rossetti [5] and by Jaatinen and Rintala [6]. However, beyond the neurotransmittal mechanisms, a body of evidence revealed that EW stimulates the pathways of unstable oxidative molecules and stressresponding signaling proteins (e.g. PKC and P38). Unfortunately, many alcohol studies did not differentiate between ethanol exposure and EW and thus it is not clear whether the reported injuries/mechanisms are associated with ethanol toxicity, EW, or both. In order to differentiate the effects of EW from those of ethanol exposure, tissues or cells should be collected in the optimum hours after ethanol is completely eliminated from blood or cell cultures. The optimum hours vary depending upon an ethanol regimen. In our model of EW, severe neurochemical abnormalities were observed in the brains harvested 24 hours after the termination of chronic ethanol consumption (35 or 90 days) or in cells withdrawn for 4 hours from 24 hours-ethanol exposure. EW-induced seizure was observed 1 or 3 days after the cessation of an ethanol diet for 14 days [7]. The differentiation between ethanol and EW stress is important because the deleterious effects of EW are not necessarily identical to those of ethanol per se and can cause more brain damage. In support of this idea, ethanol treatment followed by withdrawal resulted in a neuronal loss in the mouse hippocampus [8] and rat cerebellum [9], whereas ethanol per se did not cause any neuronal loss. EW but not ethanol exposure resulted in shrinkage and disintegration of neuritic processes and cell bodies in primary cortical neurons [10]. Similarly, EW but not ethanol exposure decreased the cyclic AMP-response element-binding proteins, a $\mathrm{Ca}^{2+}$-dependent kinase in the cortex [11], and a $\mathrm{Ca}^{2+}$ buffering protein parvalbumin [12]. Repeated $\mathrm{EW}$, but not an equivalent amount of continuous ethanol exposure, impaired the learning ability associated with amygdale [13,14]. In line with these greater disturbing effects of EW than ethanol, De Witte et al. [2] stated that neuroadaptations occur within the CNS during alcohol dependence, allowing the brain to function regularly while being disturbed by alcohol. We did observe that although both 
ethanol and EW produced oxidative damages to lipids and proteins in rats and cells $[15,16]$, the degree was more severe during EW, suggesting that EW is distinct from ethanol exposure per se.

\section{EW \& Oxidative Stress}

\subsection{Oxidative stress}

Reactive oxygen species (ROS) are produced under physiological conditions as byproducts of redox reactions but the endogenous antioxidant defense system usually scavenges them. However, under pathological conditions, the excessive generation of ROS overcomes the defense system and triggers the cascade of deleterious molecular events called oxidative stress. A moderate generation of ROS can be beneficial for cell survival by enhancing adaptive mechanisms [17,18]. The current review article discusses mainly a deleterious degree of oxidative stress. Oxidative stress-induced neuronal damage has been implicated in neurodegenerative disorders including those associated with ethanol consumption and EW. While ethanol itself directly generates ROS during its metabolism, EW produces oxidative stress indirectly through the excitatory neurotransmitter system or excitatory molecules such as $\mathrm{Ca}^{2+}$ [19]. EW-induced ROS subsequently promote lipid peroxidation which reflects the interaction between oxygen and the polyunsaturated fatty acids of membrane lipids (e.g. malondialdehyde), further generating deteriorating breakdown products.

A functional impairment attributed by pro-oxidant EW was seen in a study in which enhanced malondialdehyde concurred with the enhanced severity of EW syndromes [20] such as seizure activity [21-23]. The pro-oxidant nature of ethanol or EW is particularly important in the CNS because CNS consists of a high content of unsaturated membrane lipids, which are a preferred target of both ROS and lipid peroxidation [24,25]. In addition, despite that the brain has a high oxidative metabolic rate, it has low levels of antioxidant enzymes compared to other organs [26]. We did observed that excessive lipid peroxidation occurred in the ethanol withdrawn rat cerebellum and this phenomenon was more severe in the membrane fraction than the cytosol fraction [27]. These studies suggest that the membranous structure of brain provides a favorable condition to EW insults. The membrane targeting effect of EW is also seen in a clinical situation in which the membrane fluidity of erythrocytes was altered in ethanol withdrawn alcoholic patients [28]. EW-induced oxidative stress appears to be transient under a certain condition. Marotta et al. [29] stated that the oxidative phenomena occur in the early phase of EW rather than the late phase. In agreement, an increased level of malondialdehyde during early detoxification in alcoholic patients decreased within a few days [20,30]. In our animal study, lipid peroxidation peaked at 24 hours of EW and diminished toward the control level after 2-4 days of withdrawal [27]. Such transient oxidative insults may not immediately result in neuronal death because no TUNEL (marker of DNA fragmentation) positive cells were detected at 48 hours of EW (data not shown). Ulrichsen et al. also showed no hippocampal neuronal loss during the early EW phase after multiple EW events in rats [31]. Although the levels of these oxidative markers are decreased as the day of EW elapses, the significantly elevated levels of oxidative molecules during the acute phase of EW may trigger downstream adverse effectors, ultimately contributing to neuronal damages. In fact, rat cerebellum obtained two weeks after the termination of an ethanol diet (five weeks, $6.5 \% \mathrm{v} / \mathrm{v} /$ ) showed a loss of Purkinje neurons [9]. The EW-induced neuronal damage may be 
promoted by an excitatory neurotransmission such as the glutamatergic system based on a report that the inhibition of glutamate transporters (terminator of glutamatergic neurotransmission) generated ROS in the rat hippocampus [32]. Therefore, it is possible that an additive or a synergistic effect of ROS with glutamate may exacerbate the neuronal loss. Indeed, Coyle and Puttfarcken [33] stated that the persistent activation of glutamate-gated ion channels and oxidative stress are interacting processes which provide a final common pathway for cell vulnerability in the brain. On the other hand, one cannot exclude a possibility that the levels of oxidative markers may remain elevated for longer than a few days depending upon the severity of EW or the type of brain injuries.

\subsection{Protein oxidation}

The pro-oxidant effects of EW are also seen at the protein level. Protein oxidation is particularly important because neurodegenerative diseases and aging are associated with the oxidative modification of proteins $[34,35]$. ROS attack proteins, resulting in the formation of protein carbonyls and subsequently inactive proteins. Therefore, augmented carbonyl contents have been measured as a cellular marker of oxidative damage to proteins [36,37]. The protein carbonyl content was increased in the blood of ethanol-dependent patients [38] and in the liver or pancreas of ethanol exposed rats and mice [39-41]. Similarly, an increased content of protein carbonyls was observed in the cerebellum, cortex, and hippocampus of ethanol consuming rats [16]. Importantly, the level of protein carbonyls was further increased during EW [16], suggesting that abrupt EW produces more severe protein oxidation than ethanol per se.

The mechanisms by which EW provokes oxidative stress/damage have been characterized in our in vitro immortalized hippocampal cell line (HT22 cell). This cell line is an effective model of oxidative stress. HT22 cells contain the glutamate/cystine antiporter for the delivery of cystine into neuronal cells that mediates the synthesis of an antioxidant glutathione. Therefore, HT22 cellular injury is often associated with oxidative insults [42,43] including EW-induced cellular oxidation [44]. As was the case for in vivo studies, HT22 cells withdrawn for four hours after ethanol exposure for 24 hours encountered an excess generation of ROS and protein carbonylation. The oxidative stress was more severe during EW than ethanol exposure per se and was accompanied with cell death. Taken together, these findings suggest that EW induces destructive oxidative stress both in in vivo and in vitro conditions.

\subsection{Antioxidant mechanisms of E2}

$17 \beta$-Estradiol (E2, Figure 1) is the most potent naturally occurring estrogen. Beyond its effect on reproductive organs, the neuroprotective activities of E2 have been extensively studied and proved in a variety of in vitro and in vivo neuroprotection models [45-50]. The E2's neuroprotection is the end results of well-orchestrated genomic and non-genomic processes. As a non-genomic protection, the estrogen receptor (ER)-independent antioxidant effect of $\mathrm{E} 2$ is an important contributor to cell survival against oxidative stress [51-53]. The antioxidant action occurs mainly via direct free-radical scavenging, although indirect mechanisms, such as the upregulation of antioxidant enzymes and the chelation of redox-active metal ions, may also be involved [54,55]. E2 may directly scavenge free radicals through a mechanism involving a non-phenolic para-quinol from which E2 can be efficiently 
regenerated via a NADPH-dependent reductive aromatization (Figure 2) [53,54]. This cyclic antioxidant mechanism discovered by Prokai implies that E2 doesn't have to be used up when it provides a "chemical shield" against harmful free radicals but it can be rejuvenated. Indeed, E2 protected against the excessive generation of ROS in HT22 cells which were inflicted by a side effect of a psychiatric treatment [56].

Figure 1. Chemical structures of E2, OP, BHT and 3-OBu-E2.<smiles>CC12CCC3c4ccc(O)cc4CCC3C1CC[C@@H]2O</smiles>

$17 \beta$-Estradiol (E2)<smiles>Cc1cc(C(C)(C)C)c(O)c(C(C)(C)C)c1</smiles>

2,6-Di-tert-butyl-4-methylphenol (BHT)<smiles>CCCCCCCCc1ccc(O)cc1</smiles>

$p-\mathrm{O}$ ctylphenol (OP)

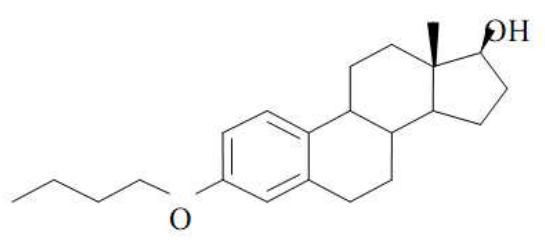

3-Butyl ether ofE2 (3-OBu-E2)

Figure 2. Schematic illustration of how estrogens provide a "chemical shield" from $\bullet \mathrm{OH}$ exposure by an antioxidant cycle discovered by Prokai [54,55]. E2 captures $\bullet \mathrm{OH}$ and produces the phenoxyl radical and subsequently a bioreversible quinol. The quinol is rapidly converted to the parent estrogen via a $\mathrm{NAD}(\mathrm{P}) \mathrm{H}$-dependent enzyme-catalyzed reductive aromatization to perpetuate the antioxidant action. During this process, $\bullet \mathrm{OH}$ is detoxified to $\mathrm{H}_{2} \mathrm{O}$ via a radical exchange reaction in the chain-breaking lipid peroxidation $(\mathrm{LOO} \rightarrow \mathrm{LOOH})$.

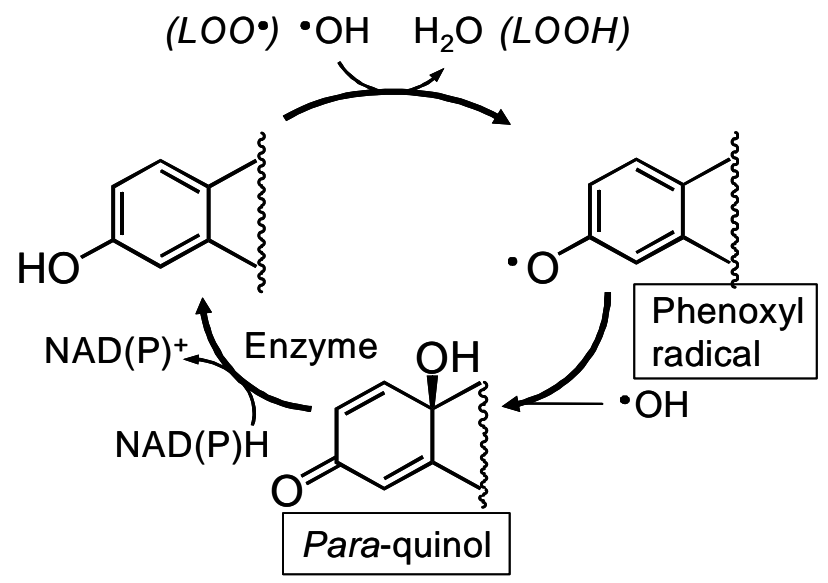

E2 also mitigated EW-induced lipid peroxidation and protein oxidation in rats and cells [16,57]. Estrogen protection against EW-induced oxidation may also involve the regulation of glutamatergic neurotransmission because glutamate-induced oxidative stress was attenuated by E2 [58,59]. 
Additionally, E2 may counteract pro-oxidant ethanol/EW through enhancing the activity of antioxidant enzymes based on a report that estrogen deficiency downregulated the activity of superoxide dismutase [60]. The downregulation of antioxidant enzymes is associated with increased production of free radicals and is prevented by estrogen replacement [60]. Furthermore, estrogens at a physiological concentration interact synergistically with the antioxidant glutathione, providing enhanced neuroprotective potency $[61,62]$. This synergy with glutathione may result from an enhancing effect of estrogen on the reducing potential of glutathione [59,63].

We recently assessed whether a free radical scavenging effect of estrogen contributes to its protection against pro-oxidant EW in HT22 cells [64]. An in vitro efficacy of E2 was compared with other phenolic compounds such as p-octylphenol (OP) and 2,6-di-tert-butyl-4-methylphenol (BHT) and a non-phenolic compound, 3-butyl ether-E2 (3-OBu-E2) in HT22 cells. 3-OBu-E2 is an E2 derivative (Figure 1) in which a phenolic $\mathrm{OH}$ is blocked by butyl ether formation [65]. If the antioxidant property of these compounds is attributed to the presence of the free phenolic $\mathrm{OH}, 3-\mathrm{OBu}-$ E2 should have no protection against EW-induced oxidation. As expected, E2, p-octylphenol, and BHT protected against EW-induced cell death and cellular oxidation whereas 3-OBu-E2 without the phenolic $\mathrm{OH}$ failed to exert the protection (Table 1). These findings suggest that the phenolic moiety of $\mathrm{E} 2$ is, indeed, an essential feature for the free radical scavenging property.

Table 1. The comparison between protective effects of phenolic and non-phenolic test compounds. HT-22 cells were exposed to 24 - hour-ethanol (200 mM) followed by 4-hoursethanol withdrawal (EW) with or without (EW only) concomitant treatment with phenolic test compounds $(1 \mu \mathrm{M}$, Figure 1) [15, 64]. In control experiments (vehicle only, no ethanol), cell viability was counted as $100 \%$, MDA level was $173 \pm 6.5 \mathrm{nmol} / \mathrm{mg} \cdot$ protein and protein carbonyl content was $1.28 \pm 0.01 \mathrm{nmol} / \mathrm{mg} \cdot$ protein.* $\mathrm{p}<0.01 \mathrm{vs}$. corresponding EW only (no test compound).

\begin{tabular}{lccccc}
\hline \multirow{2}{*}{$\%$ of control } & \multirow{2}{*}{ EW only } & \multicolumn{4}{c}{ EW + Test Compound $(\mathbf{1} \boldsymbol{\mu M})$} \\
\cline { 3 - 6 } & & E2 & BHT & OP & 3-OBu-E2 \\
\hline Cell survival & $30 \pm 1$ & $49 \pm 2^{*}$ & $50 \pm 1^{*}$ & $48 \pm 3^{*}$ & $28 \pm 3$ \\
MDA content & $219 \pm 2$ & $157 \pm 3^{*}$ & $152 \pm 1^{*}$ & $161 \pm 3^{*}$ & $220 \pm 2$ \\
Protein carbonyl & $229 \pm 3$ & $171 \pm 3^{*}$ & $174 \pm 2^{*}$ & $175 \pm 2^{*}$ & $230 \pm 3$ \\
\hline
\end{tabular}

\section{Protein Kinase}

\section{1. $P K C$}

A body of evidence indicates that oxidative stimuli are closely linked to signaling protein kinases such as protein kinase $\mathrm{C}$ (PKC) [65,66]. PKC is an important regulatory enzyme in cell fate and phosphorylates a variety of substrates such as transcription factors, membrane receptors, ion channels, and nuclear proteins. Although many functions of PKC are beneficial for cell survival [67-69], prolonged or excessive PKC activity can promote adverse downstream events [70].

The PKC family is comprised of approximately 10 different isozymes $(\alpha, \beta \mathrm{I}, \beta \mathrm{II}, \gamma, \delta, \varepsilon, \theta, \eta, \zeta$, and $1 / \lambda$ ) depending upon structural features and requirements for PKC activation [70]. Among these isozymes, $\mathrm{PKC}$ epsilon (PKC $\varepsilon$ ) has been particularly implicated in the effects of ethanol/EW effects. A 
recent in vitro study identified an ethanol-binding site in $\mathrm{PKC} \varepsilon$ [71]. Mutant mice lacking $\mathrm{PKC} \varepsilon$ consumed less ethanol and displayed less severe EW-induced seizure than wild-type mice [72]. Ethanol exposed cultured neurons showed an increase in the level of PKCE [73]. Acute ethanol treatment enhanced the activity of PKC $\varepsilon$ in the cardiac muscle [74], whereas chronic ethanol treatment decreased the activities in the cortex and hippocampus [75]. Withdrawal from forced intermittent ethanol administration for seven days enhanced the activity and protein levels of $\mathrm{PKC} \varepsilon$, whereas withdrawal from voluntary ethanol consumption for five weeks suppressed PKC $\varepsilon$ activity [76]. As such, the effect of ethanol or EW on PKC $\varepsilon$ may vary depending upon the regimen of ethanol treatment. Nevertheless, these studies suggest that PKC $\varepsilon$ is involved in the stimulus effects of ethanol dependence and EW. PKC activation may require the stimulation of resting/inactive PKC in the cytosolic compartment and its relocation to the membrane component of cells [77,78]. It has been demonstrated that ethanol exposure and EW increase the membrane translocation of PKCE [73,79]. In our previous observations, both ethanol exposure and EW increased membrane translocation and membrane protein levels of PKCE but only EW enhanced the activity of PKCE. This suggests that membrane translocation is pre-requisite but not sufficient for PKC activation. Presumably, PKC, after translocation to membrane, may have to bind to specific anchoring proteins for functional activation [80]. This process may be completed during EW but not during ethanol exposure per se.

The protective effects of estrogen on PKC $\varepsilon$ are controversial. PKC $\varepsilon$ mediates hyperalgesia caused by inflammation [81] and by chronic alcoholism [82] in a manner that was attenuated by E2 in female rats [83]. By comparison, estrogen alone without any stressful stimuli activated and induced the translocation of PKC $\varepsilon$ to the plasma membrane of cultured dorsal root ganglia neurons [84]. In our EW model, estrogen protected the homeostatic status of PKC $\varepsilon$ upon EW stress [76] and glutamate-induced cytotoxicity [85]. The mechanism(s) through which estrogen inhibits or activates PKC activity are unclear. One can speculate that an antioxidant effect of E2 may interfere with a pro-oxidant pathway associated with PKC. At concentrations that alter the intracellular distribution and activity of PKC, E2 demonstrates potent antioxidant properties in HT-22 cells [86]. Oxidants selectively react with the regulatory domain to activate PKC whereas antioxidants appear to interact with the catalytic domain to inhibit cellular PKC activity [87]. Presumably, while pro-oxidant EW activates PKC and induces the membrane translocation, the antioxidant activity of E2 stabilizes neuronal membranes, inhibits the binding of PKC to anchoring proteins, and thus prevents the functional activation of PKC [80]. Further studies need to elucidate precise mechanisms underlying the dual effects of E2 on PKC.

\section{2. $P 38$}

In addition to PKC, P38 is intimately involved in mediating EW insults. P38 belongs to the family of mitogen-activated protein kinases that mediate signaling cascades and regulate cell fate in response to cellular stress [88]. As is the case for PKC, a transient, moderate activation of P38 is associated with cell survival or differentiation, whereas a sustained or excess activation generally correlates with pathological conditions [89-91]. P38 is activated upon phosphorylation [92] and thus, pP38 is often measured as an indicator of P38 activation. Whether or not PKC (PKCE) is linked to a P38 pathway is controversial. While the overexpression of PKCE did not alter P38 activation in one study [93], a downregulation of PKCE blocked P38 activation in another study [94]. In either case, P38 is 
phosphorylated in response to stress signals such as inflammatory cytokines, heat shock or ischemia [95]. Accordingly, P38 is known as a stress-activated protein kinase. The P38 family minimally includes P38 $\alpha$ [96], P38 $\beta$ [97,98], P38 $\gamma$ [99,100] and P38 $\delta$ [101]. Among these isozymes, P38 $\alpha$ and P38 $\beta$ are highly expressed in brain areas that are vulnerable to ethanol/EW, such as cerebellum and cortex [102-104].

The signaling role of P38 in the effects of ethanol has been demonstrated such that P38 inhibitor SB203580 attenuated ethanol-induced HT22 cell death [105]. Acute ethanol treatment provoked P38 activation [106] and augmented endotoxin-induced pP38 levels in human monocytes [107]. Our recent study identified that P38 is activated more severely during EW than during ethanol exposure in male and female rats [108]. Because P38 activation has both beneficial [109] and deleterious [110] effects, we tested the effects of EW-induced P38 activation on cell survival. When P38 inhibitor (SB208035) was administered during EW, HT22 cells survived from EW-induced cytotoxicity. By comparison, the protection was lost when SB208035 was administered during ethanol exposure per se. Given this, it appears that an excessive activation of this kinase is toxic to cells and EW-induced rather than ethanolinduced activation of $\mathrm{P} 38$ contributes to the EW cytotoxicity.

It is not well understood how EW provokes P38 activation. As one possible mechanism, EWinduced glutamate neurotransmission may be involved in this process based on a study in which glutamate increased P38 phosphorylation in cultured chick cerebellar glial cells [111]. Another potential mechanism is inferred from studies in which oxidative stress was attributed to P38 activation $[112,113]$. When SB203580 (P38 inhibitor) treatment was restricted to the EW phase, it attenuated ROS generation in HT22 cells. These studies suggest that EW induces a deleterious interaction between oxidative pathways and P38 activation, contributing to cellular and neuronal damages.

Protective effects of E2 are also shown at the level of P38. E2 attenuated the phosphorylation of P38 induced by angiotensin II in cells [114], cardiac hypertrophy in ovariectomized mice [115], and myocardial inflammation in ovariectomized rats [116]. Valles et al. [113] suggested that E2 prevented oxidative stress, which in turn inhibited P38 activation and protected neurons from Amyloid $\beta$-toxicity. In our recent study, EW increased the number of cerebellar Purkinje neurons containing pP38 and E2 treatment decreased it toward a control level (Figure 3). In contrast, trauma-hemorrhage decreased the protein level of pP38, and E2 treatment increased it toward a control level [117]. It is not clear what mediates the inhibiting and the activating effects of E2 on P38. At the very least, E2 may modulate the pathological conditions of P38 in a direction toward the homeostatic status of P38.

\section{EW \& Mitochondria}

The primary function of mitochondria is to produce cellular energy (ATP) through a series of mitochondrial enzyme complexes located in the inner mitochondrial membranes. Electrons are transferred across the enzyme complexes and create the electrochemical gradient between the mitochondrial membranes. Subsequently, the electrochemical gradient provides a force to generate ATP. In the process of the electron transfer, ROS such as superoxide are typically generated as byproducts. However, the levels of ROS increase dramatically under certain pathological conditions such as EW, resulting in significant cellular and neuronal damages. 
Figure 3. Immunohistochemical detection of pP38 expression in the cerebellum. Ovariectomized rats implanted with oil pellets or E2 pellets began a 25-day-ethanol $(6.5 \%)$ and 5-day-withdrawal, repeating 3 times. The ethanol-exposure group continuously received an ethanol-diet until the very end of a diet program and was gradually withdrawn. At the 14th day of the last EW, the left hemisphere containing the cerebellar vermis was processed for immunohistochemical analysis to locate pP38 protein. Dark deposits marked with arrows indicate pP38 positive neurons or cells in the Purkinje $(\mathrm{P})$ and granular $(\mathrm{G})$ layers. A magnification of a 20 -fold was used to take pictures. A scale bar indicates an actual length of $200 \mu \mathrm{m}$.

Dextrin
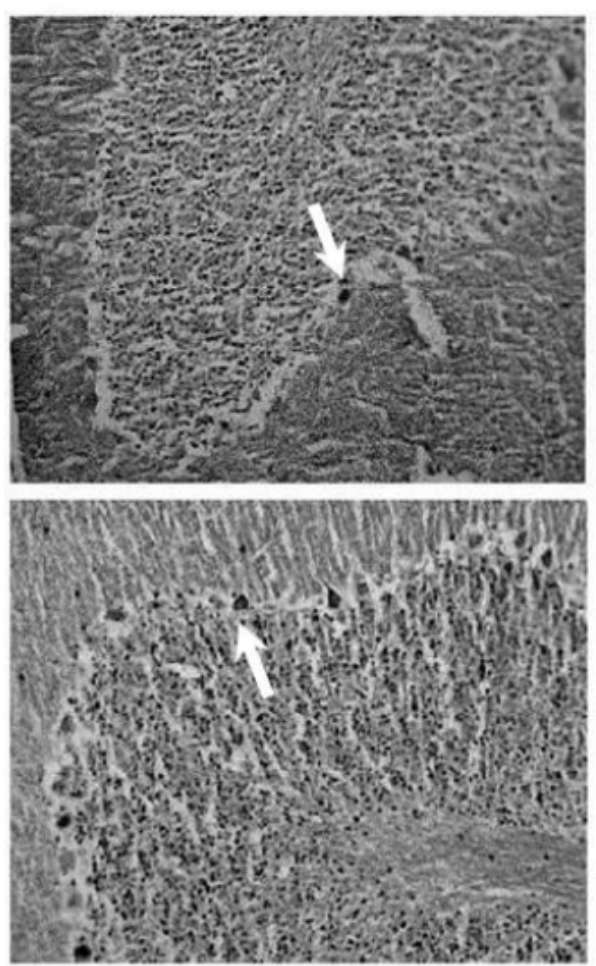

Ethanol Withdrawal

\section{Ethanol Exposure}
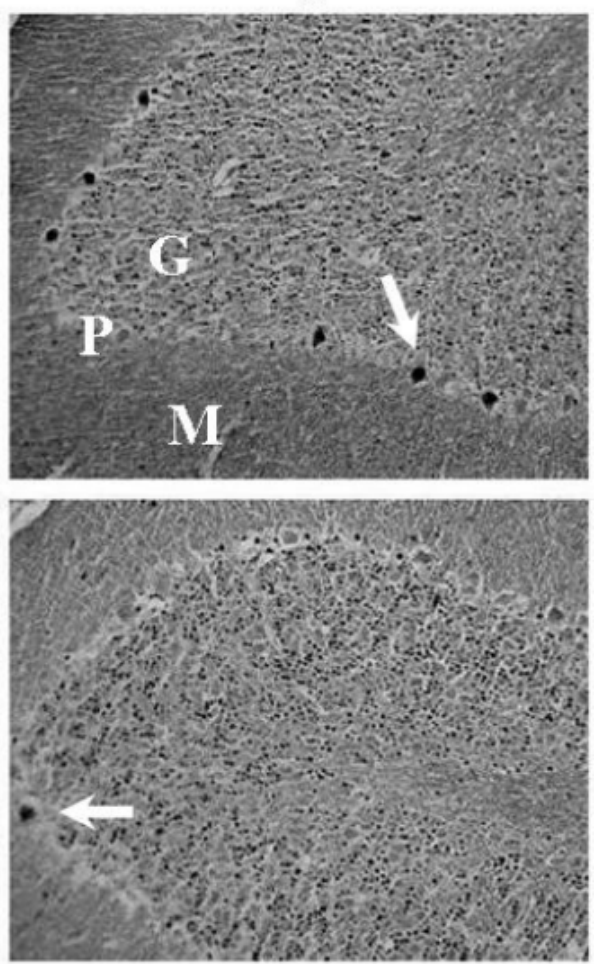

Ethanol Withdrawal

+ Estrogen

Exogenously applied $\mathrm{H}_{2} \mathrm{O}_{2}$ increased mitochondrial protein oxidation in conjunction with ATP depletion in cultured human fibroblasts [118] and human lens epithelial cells [119]. Acute administration of ethanol $(5 \mathrm{~g} / \mathrm{kg}$, IP) to mice depleted mitochondrial DNA in heart, liver, and brain [120]. ROS produced during ethanol metabolism altered mitochondrial function [120,121]. Mitochondrially targeted vitamin E protected cerebellar granule cells from ethanol-cytotoxicity [122], suggesting that oxidative insults to mitochondria intimately influence cell fate. The integrity of mitochondria is intimately affected by membrane permeability that is regulated by a group of proteins called the mitochondrial membrane permeability transition pore (PTP). PTP regulates permeability to electrolytes, nucleotides and metabolic substrates, all of which are essential for ATP production. Although the composition of PTP remains uncertain, PTP is believed to be minimally composed of adenine nucleotide translocase, mitochondrial creatine kinase, voltage dependent anion channel, and 
cyclophilin D [123-125]. Oxidative or apoptotic stress renders excess opening of PTP, diffusing water and electrolytes across the mitochondrial membranes. Consequently, mitochondrial membrane potential $(\Delta \psi \mathrm{m})$ collapses and oxidative phosphorylation of ATP fails [126]. Due to such a close relationship between PTP and $\Delta \psi \mathrm{m}, \Delta \psi \mathrm{m}$ is often measured as a typical marker of PTP.

Studies suggest a deleterious effect of ethanol or EW on PTP. For instance, ethanol-induced cell death was prevented by cyclosporin A treatment (PTP inhibitor) [121,127]. Ethanol treatment resulted in excess PTP opening in mice lacking superoxide dismutase (endogenous antioxidant enzyme) [128], suggesting that a loss of endogenous antioxidant capacity may trigger PTP opening. We have demonstrated that EW provokes mitochondrial membrane swelling and $\Delta \psi \mathrm{m}$ collapse more severely than ethanol per se [44]. There are a few possible explanations on how EW targets mitochondrial membranes. First, EW provokes the excessive generation of free radicals which readily attack mitochondrial membrane components perhaps including PTP proteins. The oxidative modification of proteins alters the stability, conformation, activity, and function of the PTP proteins, resulting in PTP opening [129]. Second, excessive glutamate-induced neuronal excitation increases intracellular concentrations of $\mathrm{Ca}^{2+}$, which provokes PTP opening [37,124,130-133]. The interaction between $\mathrm{Ca}^{2+}$ and EW is shown such that a blockade of $\mathrm{Ca}^{2+}$ channels reduced EW signs [134] and EW-induced hyperanalgesia [135]. In addition, EW depleted the level of $\mathrm{Ca}^{2+}$ buffing protein (parvalbumin) in rats [12]. This effect of EW [12] is not surprising because parvalbumin is localized in GABAergic neurons [136] which are downregulated during EW. Third, protein kinases may mediate the mitopathic process such that oxidative stress induces translocation of PKCE to mitochondria, which in turn inhibits the electron transport chain and ATP production [137]. In our pilot study, a P38 inhibitor protected against EW-induced mitochondrial membrane swelling in HT22 cells. This protection may result from a counteracting effect of the $\mathrm{P} 38$ inhibitor on a proapoptotic protein bcl-2-associated $\mathrm{x}$ protein (BAX) [138]. P38 induces the translocation of BAX to mitochondria, thereby inflicting mitochondrial integrity [138]. This effect of BAX or P38 may be facilitated by EW-induced $\mathrm{Ca}^{2+}$. Two lines of studies support this notion. A synergistic interaction between intracellular $\mathrm{Ca}^{2+}$ and cytosolic BAX induces in vitro apoptosis [139] and $\mathrm{Ca}^{2+}$ mediates glutamate-induced P38 activation [140]. The multiple interactions between P38, BAX, oxidative stress, and mitochondria were well characterized in SH-SY5Y neuroblastoma cells: a pro-oxidant malonate activated P38 and a P38 inhibitor blocked malonate-induced BAX translocation to mitochondria [141]. Finally, EW may target key mitochondrial enzymes such as COX, thereby inflicting mitochondrial membrane integrity. COX catalyzes electron transfer at the terminal stage of the respiratory chain. The suppressed activity of COX has been found in a variety of neurodegenerative illnesses such as Alzheimer's disease [142], suggesting a critical link between COX and CNS disorders. Moreover, this mitochondrial enzyme is also a target of oxidative stress such that nanomolar concentrations of nitric oxide rapidly inhibited the activity of COX in isolated mitochondria, brain nerve terminals, and cells [143]. Directly relevant to EW, repeated EW suppressed the activity of COX in the brain of young and aged rats [144]. Taken together, upon EW insults, multiple factors including $\mathrm{ROS}, \mathrm{Ca}^{2+}$, and P38 simultaneously or sequentially interact with each other, inflicting the functional impairment of mitochondrial membranes (Figure 4). 
Figure 4. Oxidative signaling pathways of EW stress. The abrupt termination of excessive ethanol exposure downregulates inhibitory GABA (1) and upregulates excitatory glutamate (2) neurotransmittions. The excitatory stimulus of ethanol withdrawal (EW) provokes ROS generation (3), inducing the oxidation of lipid and proteins (4). ROS also trigger downstream effectors such as the activation and translocation of PKCE (5), the phosphorylation of P38 (6), and an increase in the intracellular level of $\mathrm{Ca}^{2+}$ (7). A mutually enhancing effect (8) of ROS and glutamate may increase the activation of P38. The $\mathrm{Ca}^{2+}$ overload induced by glutamate (9) or by ROS is buffered by a $\mathrm{Ca}^{2+}$ buffering protein parvalbumin (10). Parvalbumin, located in GABAergic neurons, is downregulated in conjunction with EW-induced suppression of GABA neurotransmittions (11). The activation of P38 in turn activates BAX (12), which is inhibited by an antiapoptotic protein Bcl2 (13). Subsequently, BAX translocates to and inflicts mitochondria (14). Because mitochondria are the major source of ROS production, EW-induced excessive generation of ROS intimately impairs the integrity of mitochondrial membranes (15). Accordingly, the opening of PTP is increased, $\Delta \Psi \mathrm{m}$ collapses, and the activity of cytochrome c oxidase (COX) is suppressed, all of which provoke ATP depletion (16). As net outcomes, neurons such as cerebellar Purkinje neurons are degenerated with behavioral impairments.

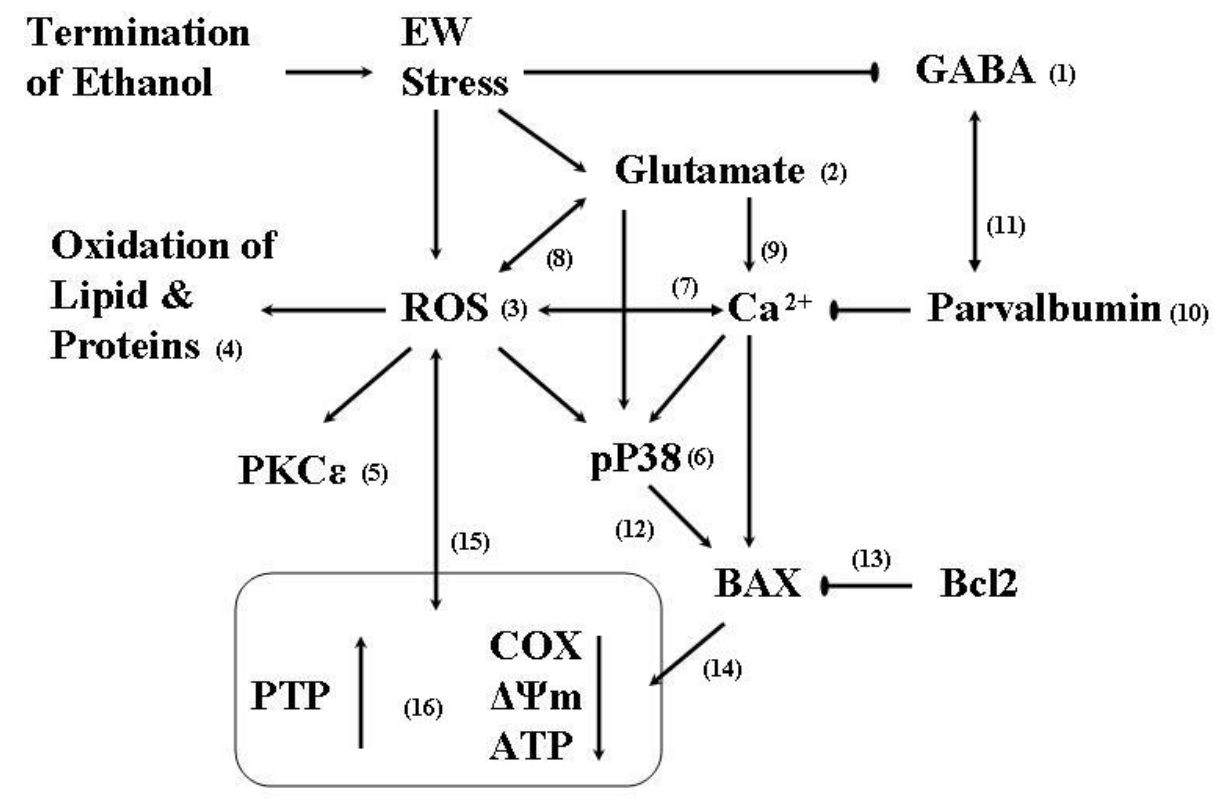

\section{Mitochondria}

We have demonstrated that EW decreased the activities of total COX in rats [145] in a manner that was prevented by E2 treatment. Estrogens have substantial effects on mitochondrial function [146], particularly in the face of stress. Estrogen exerted protection against $\beta$-amyloid- or ROS-induced mitotoxicity [146]. In a rat model of oxidative stress, E2 prevented mitochondrial peroxidation induced by ovariectomy [147]. In vitro estrogen treatment to human neuroblastoma cells also protected against ATP depletion, $\Delta \Psi \mathrm{m}$ collapse, and ROS generation induced by mitochondrial toxins [148] or $\mathrm{H}_{2} \mathrm{O}_{2}$ [116]. These mitoprotective effects of estrogen correlated with its antioxidant effects [119]. Furthermore, non-feminizing estrogens such as $17 \alpha$-estradiol and ent-estradiol shared the ability of E2 
to protect ATP production and $\Delta \Psi \mathrm{m}$ maintenance [149]. In Wang's study [149], the ER antagonist ICI 182,780 failed to block the mitoprotection exerted by these estrogen analogues, suggesting that ER independent non-genomic mechanisms [150] mediate the protection. This non-genomic mechanism of E2 is supported by Alele and Devaud's study [7] in which E2 and the neuroactive steroid pregnanolone rapidly mitigated EW-induced seizure activity. The non-genomic E2's protection appears to occur at the mitochondrial level through modulating protein-protein interaction. For instance, E2 activates an antiapoptotic protein $\mathrm{Bcl} 2$ [151] which in turn inhibits the effect of a proapoptotic protein BAX on mitochondria. Given these findings, estrogen seems to play a role in alleviating oxidative or apoptotic burden in mitochondria, thereby protecting mitochondrial functions such as mitochondrial respiration [152].

As mentioned earlier, if pro-oxidants provoke PTP opening [129], antioxidants should inhibit the opening. Indeed, PTP opening was inhibited by vitamin $\mathrm{E}$ but was induced by $\mathrm{H}_{2} \mathrm{O}_{2}$ [153,154]. Based on these studies, we assessed antioxidant protection against PTP opening using three compounds which have ROS scavenging activities: E2, an antioxidant BHT, and an E2 analogue ZYC26. ZYC26 previously showed a 10-fold higher antioxidant potency than E2 in the HT22 cell model of EW [15]. ZYC26 contains an adamantyl group at the $\mathrm{C} 2$ position of A-ring and this structural configuration enhances the stability of the adjacent phenoxyl radical, which is an essential element of ROS scavenging activity $[51,53,155]$. We computed the magnitude by which these three compounds protect HT22 cells from EW-induced mitochondrial membrane swelling. Despite that ZYC26 more potently scavenged ROS than E2, all three compounds mitigated the mitochondrial membrane swelling with a similar degree of potency (data not shown). These observations indicate that other factors, in addition to the ROS scavenging activities of E2, also mediate protection against PTP opening. For instance, E2 may activate glutathione peroxidase which directly reduces membrane-bound lipid hydroperoxides $[156,157]$. It is also possible that E2 elevates the levels of endogenous antioxidants such as glutathione so that a favorable redox potential for an antioxidant environment is created [63]. Alternatively, because high levels of mitochondrial $\mathrm{Ca}^{2+}$ impede the regulatory function of the PTP proteins [124] and E2 induces mitochondrial tolerance to $\mathrm{Ca}^{2+}$ overload [158], E2 may increase a threshold of mitochondrial $\mathrm{Ca}^{2+}$ that is required to trigger PTP opening. At the very least, E2 appears to orchestrate multiple mechanisms in addition to an antioxidant action, effectively protecting mitochondria from EW.

\section{EW \& Brain Aging}

Alcohol is a commonly abused substance among elderly people [159-161]. Moreover, due to the long lasting nature of alcoholism, many alcohol dependent individuals experience aging in the course of alcoholism. Although many studies have investigated the interaction between age and ethanol [6,144], few studies have addressed brain aging associated with EW. An interaction between functional brain aging and EW was shown in a human study in which $70 \%$ of abstinent alcoholics suffered from aging-like neuropsychological impairments, including deficits in motor performance, short-term memory, and visuospacial performance [162]. Age-dependent effects of EW are also shown in animal studies in which EW provoked neuronal loss in the locus coeruleus in old male rats (29-30 months) but not in young rats (3-4 months) [163]. Thus, EW-induced neurobehavioral deficits may 
closely resemble psychomotor aging and these two variables (age and EW) may interact adversely with one another through common mechanisms.

Both EW and aging are closely associated with oxidative stimulus. ROS are overproduced in aged subjects [164-166], and oxidative stress promotes age-related changes in cellular components [167170]. The pro-oxidant nature of EW is particularly important in brain aging because it increases oxidative stress in the areas that are most vulnerable to aging, thereby facilitating age-associated disorders [171,172]. We have determined whether EW acts as a provoking stimulus for aging-like damage at the level of motor performance and cellular redox status. Ovariectomized female rats with or without E2 implantations, completed a diet program of 25-day ethanol exposure followed by 5-day EW/cycle, repeating three cycles. They were then tested for cerebellar-related motor performance and oxidative stress. Ethanol withdrawn rats displayed significant motor deficit and severe cellular oxidation at an earlier age than control-diet rats in a manner that was ameliorated by E2. These observations suggest that EW hastens brain aging and estrogen mitigates the problem. The ageassociated motor deficit did not appear to be due to different amounts of ethanol intake or ethanol kinetics between ages. In general, old people consume a smaller amount of ethanol than young people even among alcoholic population [173]. Similarly for experimental animals, older rats consume less of an ethanol diet than young rats. In spite of the lesser ethanol intake, old rats had a higher blood ethanol concentration [174,175] and a slower ethanol elimination rate than young rats [176]. However, a higher blood ethanol concentration in old rats unlikely mediates their greater vulnerability to EW because the degree of EW-induced motor deficit did not correlate with blood ethanol concentrations. These findings suggest that the kinetics of ethanol unlikely contributes to the EW-induced motoric aging.

P38 has been implicated in age-associated physiological or pathological conditions. While old men had a higher level of basal pP38 in skeletal muscles than young men, the opposite trend in ageassociated pP38 levels occurred after strenuous exercise [177]. Mutant mice that formed the pathological aggregation of tau proteins had excess levels of pP38, which increased with age [178]. Pathological activation of P38 was shown in the brains of Alzheimer's disease patients [179] and in the livers of aged rats after challenged with $\mathrm{H}_{2} \mathrm{O}_{2}$ [180]. Given this information, we tested the hypothesis that EW acts as an age-specific stressor to activate P38 in cerebellar neurons. Although the cerebellum contains multiple types of neurons, Purkinje neurons constitute the single output of all motor coordination in the cerebellar cortex [181]. Therefore, damage to these neurons inevitably provokes impairment of motor behavior and motor learning. For instance, cerebellar ataxic mice had a loss of Purkinje neurons but no change in the cerebellar granular neurons [182]. Purkinje neuron knock-out mice showed more severe motor deficit in a Rotarod test than granular neuron knock-out mice [183]. The ability of the connection (synaptic plasticity) between Purkinje neurons was lost by ethanol treatment [184]. In fact, a substantial loss of these neurons coincided with motor deficit in ethanolwithdrawn rats $[9,57]$. Using immunohistochemistry, we observed that $\mathrm{pP} 38$ positive Purkinje neurons were more populated in middle-age (15 months) EW rats than young ( 8 months) or older (19 months) EW rats. Similarly, EW-induced oxidation of mitochondrial proteins was more severe in middle-age rats (15 months) than other age groups (8 and 19 months). These findings suggest that the most vulnerable age to EW insults is not necessarily the old age and may vary depending upon target molecules of EW. As far as P38 is concerned, middle-age (12-15 months) was most vulnerable among 
the age categories tested (5-8, 12-15, and 16-19 months). In addition, the localization of pP38 in ethanol-withdrawn Purkinje neurons implies that P38 activation intimately interferes with the neuronal integrity.

The susceptive neuronal response of middle-age rats to P38 activated by EW was coherent with behavioral manifestation in that EW-induced motor deficit was exacerbated by age, which began at 1215 mo. A previous study also reported the vulnerability of middle-age groups to aging symptoms such that the onset of memory impairment occurred at the age of 12 months in female rats [185]. In a clinical study, brain changes resembling Alzheimer's disease were most evident during the ages 50 to 59 years [186]. Multiple tasks involving cognitive and motor functions also declined during middleage $[187,188]$. The susceptibility of middle-age rats may be the reflection of cellular and neuronal alterations associated with transition stress from young to old endogenous systems. The variety of alterations may collectively perturb the neuronal integrity, providing favorable conditions for P38 activation upon EW insults. In this scenario, animals a few months older than the middle age may develop adaptations and tolerances to the altered cellular and neuronal milieu and thus become more resistant to the EW stress. Alternatively, age-associated alteration may depend on specific organelles or molecules. For instance, when $\boldsymbol{O}_{2}{ }^{-}$and $\mathrm{H}_{2} \mathrm{O}_{2}$ were measured in mitochondrial fractions, the content peaked in middle-age rats [189]. In comparison, when total ROS content was measured in the wholecerebellar lysates (not specific organelles), it peaked at an older age (19 months). The ROS results suggest that the vulnerable age at which maximum damage occurs may vary depending upon target molecules or organelles and the nature of stress.

Protective effects of E2 on age-associated motor deficit have been shown in studies where E2 administration improved the motor performance of 24-month-old female rats [190]. In contrast to these beneficial effects of estrogen, some studies reported adverse effects of estrogen on age-related phenomena such as decline in memory or cognition in humans [191] and in animals [192]. Among these reports, there seems to be a consistent agreement that estrogen treatment soon after ovariectomy produces beneficial effects on cognition, whereas a delayed treatment after ovariectomy has little or no beneficial effects. When treated with E2 at three months following ovariectomy, middle-aged rats learned a spatial memory task more quickly than vehicle-treated rats; however, when E2 treatment was delayed until 10 months after ovariectomy, no effects of E2 were observed [193]. Similar results were observed in studies of rhesus monkeys [191,194] and humans [195], suggesting that the neuroprotective effects of estrogen may require a certain treatment window. When implanted immediately after ovariectomy, we did observe that old, ethanol withdrawn rats treated with E2 behaved like young rats in motor performance, and showed similar cellular oxidation properties and hyperactivation of $\mathrm{P} 38$.

\section{Conclusions}

Beyond classical mechanisms of the hyperactivation of excitatory and the suppression of inhibitory neurotransmissions, EW also induces the excessive generation of oxidative molecules which trigger the cascades of downstream signaling proteins such as protein kinases. The EW-induced ROS directly or indirectly attack mitochondria through the signaling protein kinases. Consequently, mitochondrial membranes swell, membrane potential collapses, and cytochrome c oxidases loses its activity, all of 
which contribute to mitochondrial pathology. When the brain is repeatedly exposed to such chaotic events, neurons are injured with behavioral consequences, the gravity of which is exacerbated at a vulnerable age. Estrogen may interfere with upstream oxidative pathways through its antioxidant activity, thereby protecting downstream effectors. Alternatively, E2 may simultaneously regulate oxidative pathways and signaling protein kinases, collectively executing protection. In addition to oxidative signaling mechanisms that were discussed in this review, numerous other pathways and complicated interactions between them are believed to mediate EW-induced brain injuries or E2's protection. Unfortunately, it is difficult to differentiate each pathway to determine the degree to which EW or estrogen directly affects each step and how much is due to its effects on the others. It is our hope that this work contributes to a new insight into oxidative signaling pathways of EW and triggers further studies to identify molecular targets for better EW management.

\section{References and Notes}

1. Barrett, R. Behavioral Approaches to Individual Differences in Substance Abuse. In Determinants of Substance Abuse: Biological, Pyschological, and Environmental Factors; Schaffer, H., Galizio, M., Maisto, S.A., Eds.; Plenum Press: New York, NY, USA, 1985; pp. $125-174$.

2. De Witte, P.; Pinto, E.; Ansseau, M.; Verbanck, P. Alcohol and withdrawal: from animal research to clinical issues. Neurosci. Biobehav. Rev. 2003, 27, 189-197.

3. Mandrekar, P.; Catalano, D.; Jeliazkova, V.; Kodys, K. Alcohol exposure regulates heat shock transcription factor binding and heat shock proteins 70 and 90 in monocytes and macrophages: Implication for TNF-alpha regulation. J. Leukoc. Biol. 2008, 84, 1335-1345.

4. Li, S.Y.; Ren, J. Cardiac overexpression of alcohol dehydrogenase exacerbates chronic ethanol ingestion-induced myocardial dysfunction and hypertrophy: Role of insulin signaling and ER stress. J. Mol. Cell Cardiol. 2008, 44, 992-1001.

5. Fadda, F.; Rossetti, Z.L. Chronic ethanol consumption: From neuroadaptation to neurodegeneration. Prog. Neurobiol. 1998, 56, 385-431.

6. Jaatinen, P.; Rintala, J. Mechanisms of ethanol-induced degeneration in the developing, mature, and aging cerebellum. Cerebellum 2008, 7, 332-347.

7. Alele, P.E.; Devaud, L.L. Sex differences in steroid modulation of ethanol withdrawal in male and female rats. J. Pharmacol. Exp. Ther. 2007, 320, 427-436.

8. Phillips, S.C.; Cragg, B.G. Chronic consumption of alcohol by adult mice: Effect on hippocampal cells and synapses. Exp. Neurol. 1983, 80, 218-226.

9. Jung, M.E.; Yang, S.H.; Brun-Zinkernagel, A.M.; Simpkins, J.W. Estradiol protects against cerebellar damage and motor deficit in ethanol-withdrawn rats. Alcohol 2002, 26, 83-93.

10. Nagy, J.; Muller, F.; Laszlo, L. Cytotoxic effect of alcohol-withdrawal on primary cultures of cortical neurones. Drug Alcohol Depend 2001, 61, 155-162.

11. Pandey, S.C.; Roy, A.; Mittal, N. Effects of chronic ethanol intake and its withdrawal on the expression and phosphorylation of the creb gene transcription factor in rat cortex. J. Pharmacol. Exp. Ther. 2001, 296, 857-868. 
12. Rewal, M.; Wen, Y.; Wilson, A.; Simpkins, J.W.; Jung, M.E. Role of parvalbumin in estrogen protection from ethanol withdrawal syndrome. Alcohol Clin. Exp. Res. 2005, 29, 1837-1844.

13. Ripley, T.L.; O'Shea, M.; Stephens, D.N. Repeated withdrawal from ethanol impairs acquisition but not expression of conditioned fear. Eur. J. Neurosci. 2003, 18, 441-448.

14. Stephens, D.N.; Brown, G.; Duka, T.; Ripley, T.L. Impaired fear conditioning but enhanced seizure sensitivity in rats given repeated experience of withdrawal from alcohol. Eur. J. Neurosci. 2001, 14, 2023-2031.

15. Jung, M.E.; Wilson, A.M.; Simpkins, J.W. A nonfeminizing estrogen analog protects against ethanol withdrawal toxicity in immortalized hippocampal cells. J. Pharmacol. Exp. Ther. 2006, 319, 543-550.

16. Jung, M.E.; Yan, L.J.; Forster, M.J.; Simpkins, J.W. Ethanol withdrawal provokes mitochondrial injury in an estrogen preventable manner. J. Bioenerg. Biomembr. 2008, 40, 35-44.

17. Kim, J.; Jang, H.S.; Park, K.M. Reactive oxygen species generated by renal ischemia and reperfusion trigger protection against subsequent renal ischemia and reperfusion injury in mice. Am. J. Physiol. Renal. Physiol. 2009, 289, F158-F166.

18. Mallet, R.T.; Ryou, M.G.; Manukhina, E.B.; Downey, H.F. Intermittent Hypoxia Conditioning of Canine Myocardium: Robust Protection against Ischemia-reperfusion Injury. In Adaptation Biology and Medicine, 1st ed.; Lukyanova, L., Takeda, N., Singal, P.K., Ed.; Narosa Pub. House: New Delhi, India, 2008; Volume 5, pp. 59-78.

19. Fujikawa, D.G. Prolonged seizures and cellular injury: Understanding the connection. Epilepsy Behav. 2005, 7, S3-S11.

20. Huang, M.C.; Chen, C.H.; Peng, F.C.; Tang, S.H.; Chen, C.C. Alterations in oxidative stress status during early alcohol withdrawal in alcoholic patients. J. Formos. Med. Assoc. 2009, 108, 560-569.

21. Grattagliano, I.; Vendemiale, G.; Errico, F.; Bolognino, A.E.; Lillo, F.; Salerno, M.T.; Altomare, E. Chronic ethanol intake induces oxidative alterations in rat testis. J. Appl. Toxicol. 1997, 17, 307-311.

22. Tsai, G.E.; Ragan, P.; Chang, R.; Chen, S.; Linnoila, V.M.; Coyle, J.T. Increased glutamatergic neurotransmission and oxidative stress after alcohol withdrawal. Am. J. Psychiat. 1998, 155, 726-732.

23. Vallett, M.; Tabatabaie, T.; Briscoe, R.J.; Baird, T.J.; Beatty, W.W.; Floyd, R.A.; Gauvin, D.V. Free radical production during ethanol intoxication, dependence, and withdrawal. Alcohol Clin. Exp. Res. 1997, 21, 275-285.

24. Adachi, J. Membrane disorder and free radical. Nihon Hoigaku Zasshi 2000, 54, 356-360.

25. Lehotsky, J.; Kaplan, P.; Matejovicova, M.; Murin, R.; Racay, P.; Raeymaekers, L. Ion transport systems as targets of free radicals during ischemia reperfusion injury. Gen. Physiol. Biophys. 2002, 21, 31-37.

26. Shulman, R.G.; Rothman, D.L.; Behar, K.L.; Hyder, F. Energetic basis of brain activity: Implications for neuroimaging. Trends Neurosci. 2004, 27, 489-495.

27. Jung, M.E.; Rewal, M.; Perez, E.; Wen, Y.; Simpkins, J.W. Estrogen protects against brain lipid peroxidation in ethanol-withdrawn rats. Pharmacol. Biochem. Behav. 2004, 79, 573-586. 
28. Thompson, P. Platelet and erythrocyte membrane fluidity changes in alcohol-dependent patients undergoing acute withdrawal. Alcohol Alcohol. 1999, 34, 349-354.

29. Marotta, F.; Reizakovic, I.; Tajiri, H.; Safran, P.; Ideo, G. Abstinence-induced oxidative stress in moderate drinkers is improved by bionormalizer. Hepatogastroenterology 1997, 44, 1360-1366.

30. Bleich, S.; Spilker, K.; Kurth, C.; Degner, D.; Quintela-Schneider, M.; Javaheripour, K.; Ruther, E.; Kornhuber, J.; Wiltfang, J. Oxidative stress and an altered methionine metabolism in alcoholism. Neurosci. Lett. 2000, 293, 171-174.

31. Ulrichsen, J.; Woldbye, D.P.; Olsen, C.H.; Haugbol, S.; Bolwig, T.G.; Hemmingsen, R. No loss of somatostatin-immunoreactive neurons in the hippocampal dentate hilus of alcohol-withdrawalkindled rats. Alcohol Alcohol. 1996, 31, 411-419.

32. Nagatomo, K.; Ueda, Y.; Doi, T.; Nakajima, A. An acute dysfunction of the glutamate transport activity has been shown to generate free radicals and suppress the anti-oxidant ability in the hippocampus of rats. Neurosci. Res. 2007, 57, 477-480.

33. Coyle, J.T.; Puttfarcken, P. Oxidative stress, glutamate, and neurodegenerative disorders. Science 1993, 262, 689-695.

34. Dalle-Donne, I.; Giustarini, D.; Colombo, R.; Rossi, R.; Milzani, A. Protein carbonylation in human diseases. Trends Mol. Med. 2003, 9, 169-176.

35. Levine, R.L. Carbonyl modified proteins in cellular regulation, aging, and disease. Free Radical Biol. Med. 2002, 32, 790-796.

36. Rauniyar, N.; Stevens, S.M., Jr.; Prokai-Tatrai, K.; Prokai, L. Characterization of 4-hydroxy-2nonenal-modified peptides by liquid chromatography-tandem mass spectrometry using datadependent acquisition: Neutral loss-driven MS3 versus neutral loss-driven electron capture dissociation. Anal. Chem. 2009, 81, 782-789.

37. Prokai, L.; Yan, L-Y; Vera-Serrano, J,V.; Stevens, S.M., Jr.; Forster, M.J. Mass spectrometrybased survey of age-associated protein carbonylation in rat brain mitochondria. J. Mass Spectrom. 2007, 42, 1583-1589.

38. Mutlu-Turkoglu, U.; Dogru-Abbasoglu, S.; Aykac-Toker, G.; Mirsal, H.; Beyazyurek, M.; Uysal, M. Increased lipid and protein oxidation and DNA damage in patients with chronic alcoholism. $J$. Lab. Clin. Med. 2000, 136, 287-291.

39. Bailey, S.M.; Patel, V.B.; Young, T.A.; Asayama, K.; Cunningham, C.C. Chronic ethanol consumption alters the glutathione/glutathione peroxidase-1 system and protein oxidation status in rat liver. Alcohol Clin. Exp. Res. 2001, 25, 726-733.

40. Cano, M.J.; Ayala, A.; Murillo, M.L.; Carreras, O. Protective effect of folic acid against oxidative stress produced in 21-day postpartum rats by maternal-ethanol chronic consumption during pregnancy and lactation period. Free Radical Res. 2001, 34, 1-8.

41. Zhou, Z.; Wang, L.; Song, Z.; Saari, J.T.; McClain, C.J.; Kang, Y.J. Zinc supplementation prevents alcoholic liver injury in mice through attenuation of oxidative stress. Am. J. Pathol. 2005, 166, 1681-1690.

42. Khomenko, I.P.; Bakhtina, L.Y.; Zelenina, O.M.; Kruglov, S.V.; Manukhina, E.B.; Bayda, L.A.; Malyshev, I.Y. Role of heat shock proteins HSP70 and HSP32 in the protective effect of adaptation of cultured HT22 hippocampal cells to oxidative stress. Bull. Exp. Biol. Med. 2007, 144, 174-177. 
43. Rackova, L.; Snirc, V.; Jung, T.; Stefek, M.; Karasu, C.; Grune, T. Metabolism-induced oxidative stress is a mediator of glucose toxicity in HT22 neuronal cells. Free Radical Res. 2009, 43, 876-886.

44. Jung, M.E.; Wilson, A.M.; Ju, X.; Wen, Y.; Metzger, D.B.; Simpkins, J.W. Ethanol withdrawal provokes opening of the mitochondrial membrane permeability transition pore in an estrogenpreventable manner. J. Pharmacol. Exp. Ther. 2009, 328, 692-698.

45. Merchanthaler, I.; Dellovade, T.L., Shughrue, P.J. Neuroprotection by estrogen in animal models of global and focal ischemia. Ann. NY Acad. Sci. 2006, 10007, 89-100.

46. Garcia-Segura, L.M.; Azcoitia, I.; DonCarlos, L.L. Neuroprotection by estradiol. Prog. Neurobiol. 2001, 63, 29-60.

47. Riu, R.; Yang, S.H.; Perez, E.; Yi, K.D.; Wu, S.S.; Eberst, K.; Prokai, L.; Prokai-Tatrai, K.; Cai, Z.Y.; Covey, D.F.; Day, A.L.; Simpkins, J.W. Neuroprotective effects of a novel non-receptor binding estrogen analogue: in vitro and in vivo analysis. Stroke 2002, 33, 2485-2491.

48. Behl, C.; Skutella, T.; Lezoualc'h, F.; Post, A.; Widmann, M.; Newton, C.J.; Holsboer, F. Neuroprotection against oxidative stress by estrogens: Structure-activity relationship. Mol. Pharmacol. 1997, 51, 535-554.

49. Topcuoglu, A.; Uzun, H.; Balci, H.; Karakus, M.; Coban, I.; Altug, T.; Aydin, S.; Topcuoglu, D.; Cakatay, U. Effects of estrogens on oxidative protein damage in plasma and tissues in ovariectomised rats. Clin. Invest. Med. 2009, 32, E133-E143

50. Moosmann, B.; Behl, C. The antioxidant neuroprotective effects of estrogens and phenolic compounds are independent from their estrogenic properties. Proc. Natl. Acad. Sci. USA 1999, 96, 8867-8872.

51. Prokai, L.; Simpkins, J.W. Structure-nongenomic neuroprotection relationship of estrogens and estrogen-derived compounds. Pharmacol. Therapeut. 2007, 114, 1-12.

52. Branna, D.W., Dhandapania, K.; Wakadea, C.; Mahesha, V.B.; Khan, M.M. Neurotrophic and neuroprotective actions of estrogen: basic mechanisms and clinical implications. Steroids 2007, 72, 382-405.

53. Prokai, L.; Prokai-Tatrai, K.; Perjesi, P.; Simpkins, J.W. Mechanistic insights into the direct antioxidant effects of estrogens. Drug Dev. Res. 2005, 66, 118-125.

54. Prokai, L.; Prokai-Tatrai, K.; Perjesi, P.; Zharikova, A.D.; Perez, J.; Liu, R. Quinol-based cyclic antioxidant mechanism in estrogen neuroprotection. Proc. Natl. Acad. Sci. USA 2003, 100, 11741-11746.

55. Prokai-Tatrai, K.; Perjesi, P.; Rivera-Portalatin, N.M; Simpkins, J.; Prokai, L. Mechanistic investigations on the antioxidant action of a neuroprotective estrogen derivative. Steroids $\mathbf{2 0 0 8}$, 73, 280-288.

56. Sagara, Y. Induction of reactive oxygen species in neurons by haloperidol. J. Neurochem. 1998, 71, 1002-1012.

57. Rewal, M.; Jung, M.E.; Wen, Y.; Brun-Zinkernagel, A.M.; Simpkins, J.W. Role of the GABAA system in behavioral, motoric, and cerebellar protection by estrogen during ethanol withdrawal. Alcohol 2003, 31, 49-61. 
58. Singer, C.A.; Figueroa-Masot, X.A.; Batchelor, R.H.; Dorsa, D.M. The mitogen-activated protein kinase pathway mediates estrogen neuroprotection after glutamate toxicity in primary cortical neurons. J. Neurosci. 1999, 19, 2455-2463.

59. Sribnick, E.A.; Ray, S.K.; Nowak, M.W.; Li, L.: Banik, N.L. 17ß-estradiol attenuates glutamateinduced apoptosis and preserves electrophysiologic function in primary cortical neurons. $J$. Neurosci. Res. 2004, 76, 688-696.

60. Strehlow, K.; Rotter, S.; Wassmann, S.; Adam, O.; Grohe, C.; Laufs, K.; Bohm, M.; Nickenig, G. Modulation of antioxidant enzyme expression and function by estrogen. Circ. Res. 2003, 93, 170-177.

61. Green, P.S.; Gridley, K.E.; Simpkins, J.W. Nuclear estrogen receptor-independent neuroprotection by estratrienes: A novel interaction with glutathione. Neuroscience 1998, 84, 7-10.

62. Gridley, K.E.; Green, P.S.; Simpkins, J.W. A novel, synergistic interaction between 17 betaestradiol and glutathione in the protection of neurons against beta-amyloid 25-35-induced toxicity in vitro. Mol. Pharmacol. 1998, 54, 874-880.

63. Prokai, L.; Prokai-Tatrai, K.; Perjesi, P.; Zharikova, A.D.; Simpkins, J.W. Quinol-based metabolic cycle for estrogens in rat liver microsomes. Drug Metab. Dispos. 2003, 31, 701-704.

64. Prokai-Tatrai, K.; Prokai, L.; Simpkins, J.W.; Jung, M.E. Phenolic compounds protect cultured hippocampal neurons against ethanol-withdrawal induced oxidative stress. Int. J. Mol. Sci. 2009, 10, 1773-1787.

65. Prokai, L.; Oon, S.M.; Prokai-Tatrai, K.; Abboud, K.; Simpkins, J.W. Synthesis and biological evaluation of $17 \beta$-alkoxyestra-1,3,5(10)-trienes as potential neuroprotectants against oxidative stress. J. Med. Chem. 2001, 44, 110-114.

66. Lee, T.Y.; Lee, K.C.; Chen, S.Y.; Chang, H.H. 6-Gingerol inhibits ROS and iNOS through the suppression of PKC-alpha and NF-kappaB pathways in lipopolysaccharide-stimulated mouse macrophages. Biochem. Biophys. Res. Commun. 2009, 382, 134-139.

67. Inagaki, K.; Hahn, H.S.; Dorn, G.W., 2nd; Mochly-Rosen, D. Additive protection of the ischemic heart ex vivo by combined treatment with delta-protein kinase $\mathrm{C}$ inhibitor and epsilon-protein kinase C activator. Circulation 2003, 108, 869-875.

68. Maher, P. How protein kinase $\mathrm{C}$ activation protects nerve cells from oxidative stress-induced cell death. J. Neurosci. 2001, 21, 2929-2938.

69. Novotny, J.L.; Simpson, A.M.; Tomicek, N.J.; Lancaster, T.S.; Korzick, D.H. Rapid estrogen receptor-alpha activation improves ischemic tolerance in aged female rats through a novel protein kinase C epsilon-dependent mechanism. Endocrinology 2009, 150, 889-896.

70. Gorin, M.A.; Pan, Q. Protein kinase C epsilon: An oncogene and emerging tumor biomarker. Mol. Cancer 2009, 8, 9.

71. Das, J.; Pany, S.; Rahman, G.M.; Slater, S.J. PKC epsilon has an alcohol-binding site in its second cysteine-rich regulatory domain. Biochem. J. 2009, 421, 405-413.

72. Olive, M.F.; Mehmert, K.K.; Nannini, M.A.; Camarini, R.; Messing, R.O.; Hodge, C.W. Reduced ethanol withdrawal severity and altered withdrawal-induced c-fos expression in various brain regions of mice lacking protein kinase C-epsilon. Neuroscience 2001, 103, 171-179. 
73. Zhou, H.Z.; Karliner, J.S.; Gray, M.O. Moderate alcohol consumption induces sustained cardiac protection by activating PKC-epsilon and Akt. Am. J. Physiol. Heart Circ. Physiol. 2002, 283, H165-H174.

74. Chen, C.; Mochly-Rosen, D. Opposing effects of delta and xi PKC in ethanol-induced cardioprotection. J. Mol. Cell Cardiol. 2001, 33, 581-585.

75. Pascale, A.; Battaini, F.; Govoni, S.; Persichella, M.; De Salvia, M.A.; Cuomo, V. Chronic low doses of ethanol affect brain protein kinase $\mathrm{C}$ and ultrasonic calls in rats. Alcohol 1997, 14, 557-561.

76. Jung, M.E.; Watson, D.G.; Wen, Y.; Simpkins, J.W. Role of protein kinase C in estrogen protection against apoptotic cerebellar cell death in ethanol-withdrawn rats. Alcohol 2003, 31, 39-48.

77. Csukai, M.; Mochly-Rosen, D. Pharmacologic modulation of protein kinase C isozymes: The role of RACKs and subcellular localisation. Pharmacol. Res. 1999, 39, 253-259.

78. Mochly-Rosen, D.; Kauvar, L.M. Modulating protein kinase C signal transduction. Adv. Pharmacol. 1998, 44, 91-145.

79. Solem, M.; Almas, J.; Rubin, E.; Thomas, A. Changes in activity and regulation of the cardiac $\mathrm{Ca} 2+$ channel (L-type) by protein kinase $\mathrm{C}$ in chronic alcohol-exposed rats. Alcohol Clin. Exp. Res. 2000, 24, 1145-1152.

80. Ron, D.; Mochly-Rosen, D. An autoregulatory region in protein kinase C: The pseudoanchoring site. Proc. Natl. Acad. Sci. USA 1995, 92, 492-496.

81. Sweitzer, S.M.; Wong, S.M.; Peters, M.C.; Mochly-Rosen, D.; Yeomans, D.C.; Kendig, J.J. Protein kinase $\mathrm{C}$ epsilon and gamma: Involvement in formalin-induced nociception in neonatal rats. J. Pharmacol. Exp. Ther. 2004, 309, 616-625.

82. Dina, O.A.; Barletta, J.; Chen, X.; Mutero, A.; Martin, A.; Messing, R.O.; Levine, J.D. Key role for the epsilon isoform of protein kinase $\mathrm{C}$ in painful alcoholic neuropathy in the rat. J. Neurosci. 2000, 20, 8614-8619.

83. Dina, O.A.; Aley, K.O.; Isenberg, W.; Messing, R.O.; Levine, J.D. Sex hormones regulate the contribution of PKCepsilon and PKA signalling in inflammatory pain in the rat. Eur. J. Neurosci. 2001, 13, 2227-2233.

84. Hucho, T.B.; Dina, O.A.; Kuhn, J.; Levine, J.D. Estrogen controls PKCepsilon-dependent mechanical hyperalgesia through direct action on nociceptive neurons. Eur. J. Neurosci. 2006, 24, 527-534.

85. Watson, D.G.; Watterson, J.M.; Lenox, R.H. Sodium valproate down-regulates the myristoylated alanine-rich $\mathrm{C}$ kinase substrate (MARCKS) in immortalized hippocampal cells: A property of protein kinase C-mediated mood stabilizers. J. Pharmacol. Exp. Ther .1998, 285, 307-316.

86. Behl, C.; Widmann, M.; Trapp, T.; Holsboer, F. 17-beta estradiol protects neurons from oxidative stress-induced cell death in vitro. Biochem. Biophys. Res. Commun. 1995, 216, $473-$ 482.

87. Gopalakrishna, R.; Jaken, S. Protein kinase C signaling and oxidative stress. Free Radical Biol. Med. 2000, 28, 1349-1361. 
88. Arimoto, K.; Fukuda, H.; Imajoh-Ohmi, S.; Saito, H.; Takekawa, M. Formation of stress granules inhibits apoptosis by suppressing stress-responsive MAPK pathways. Nat. Cell. Biol. 2008, 10, 1324-1332.

89. Barca, O.; Costoya, J.A.; Senaris, R.M.; Arce, V.M. Interferon-beta protects astrocytes against tumour necrosis factor-induced apoptosis via activation of p38 mitogen-activated protein kinase. Exp. Cell Res. 2008, 314, 2231-2237.

90. Du, J.; Yang, S.; Wang, Z.; Zhai, C.; Yuan, W.; Lei, R.; Zhang, J.; Zhu, T. Bone morphogenetic protein 6 inhibit stress-induced breast cancer cells apoptosis via both Smad and p38 pathways. $J$. Cell Biochem. 2008, 103, 1584-1597.

91. Giordano, G.; Klintworth, H.M.; Kavanagh, T.J.; Costa, L.G. Apoptosis induced by domoic acid in mouse cerebellar granule neurons involves activation of p38 and JNK MAP kinases. Neurochem. Int. 2008, 52, 1100-1105.

92. Moriguchi, T.; Toyoshima, F.; Gotoh, Y.; Iwamatsu, A.; Irie, K.; Mori, E.; Kuroyanagi, N.; Hagiwara, M.; Matsumoto, K.; Nishida, E. Purification and identification of a major activator for p38 from osmotically shocked cells. Activation of mitogen-activated protein kinase kinase 6 by osmotic shock, tumor necrosis factor-alpha, and H2O2. J. Biol. Chem. 1996, 271, 26981-26988.

93. Lee, Y.J.; Soh, J.W.; Jeoung, D.I.; Cho, C.K.; Jhon, G.J.; Lee, S.J.; Lee, Y.S. PKC epsilon mediated ERK1/2 activation involved in radiation-induced cell death in NIH3T3 cells. Biochim. Biophys. Acta 2003, 1593, 219-229.

94. Chen, N.Y.; Ma, W.Y.; Huang, C.; Ding, M.; Dong, Z. Activation of PKC is required for arsenite-induced signal transduction. J. Environ. Pathol. Toxicol. Oncol. 2000, 19, 297-305.

95. Aydin, M.V.; Sen, O.; Kayaselcuk, F.; Bolat, F.; Tufan, K.; Caner, H.; Altinors, N. Analysis and prevalence of inflammatory cells in subtypes of lumbar disc herniations under cyclooxygenase-2 inhibitor therapy. Neurol. Res. 2005, 27, 609-612.

96. Lee, J.C.; Laydon, J.T.; McDonnell, P.C.; Gallagher, T.F.; Kumar, S.; Green, D.; McNulty, D.; Blumenthal, M.J.; Heys, J.R.; Landvatter, S.W.; et al. A protein kinase involved in the regulation of inflammatory cytokine biosynthesis. Nature 1994, 372, 739-746.

97. Jiang, Y.; Chen, C.; Li, Z.; Guo, W.; Gegner, J.A.; Lin, S.; Han, J. Characterization of the structure and function of a new mitogen-activated protein kinase (p38beta). J. Biol. Chem. 1996, 271, 17920-17926.

98. Stein, B.; Yang, M.X.; Young, D.B.; Janknecht, R.; Hunter, T.; Murray, B.W.; Barbosa, M.S. p38-2, a novel mitogen-activated protein kinase with distinct properties. J. Biol. Chem. 1997, 272, 19509-19517.

99. Lechner, C.; Zahalka, M.A.; Giot, J.F.; Moller, N.P.; Ullrich, A. ERK6, a mitogen-activated protein kinase involved in $\mathrm{C} 2 \mathrm{C} 12$ myoblast differentiation. Proc. Natl. Acad. Sci. USA 1996, 93, 4355-4359.

100. Li, H.L.; Wu, S.; Rottenberg, H. Alcohol inhibits the depolarization-induced stimulation of oxidative phosphorylation in synaptosomes. J. Neurochem. 1996, 66, 1691-1697.

101. Jiang, Y.; Gram, H.; Zhao, M.; New, L.; Gu, J.; Feng, L.; Di Padova, F.; Ulevitch, R.J.; Han, J. Characterization of the structure and function of the fourth member of p38 group mitogenactivated protein kinases, p38delta. J. Biol. Chem. 1997, 272, 30122-30128. 
102. Lee, S.H.; Park, J.; Che, Y.; Han, P.L.; Lee, J.K. Constitutive activity and differential localization of p38alpha and p38beta MAPKs in adult mouse brain. J. Neurosci. Res. 2000, 60, 623-631.

103. Nonaka, Y.; Miyajima, M.; Ogino, I.; Nakajima, M.; Arai, H. Analysis of neuronal cell death in the cerebral cortex of H-Tx rats with compensated hydrocephalus. J. Neurosurg. Pediatr. 2008, $1,68-74$.

104. Xiong, W.; Kojic, L.Z.; Zhang, L.; Prasad, S.S.; Douglas, R.; Wang, Y.; Cynader, M.S. Anisomycin activates p38 MAP kinase to induce LTD in mouse primary visual cortex. Brain Res. 2006, 1085, 68-76.

105. Ku, B.M.; Lee, Y.K.; Jeong, J.Y.; Mun, J.; Han, J.Y.; Roh, G.S.; Kim, H.J.; Cho, G.J.; Choi, W.S.; Yi, G.S.; Kang, S.S. Ethanol-induced oxidative stress is mediated by p38 MAPK pathway in mouse hippocampal cells. Neurosci. Lett. 2007, 419, 64-67.

106. Norkina, O.; Dolganiuc, A.; Shapiro, T.; Kodys, K.; Mandrekar, P.; Szabo, G. Acute alcohol activates STAT3, AP-1, and Sp-1 transcription factors via the family of Src kinases to promote IL-10 production in human monocytes. J. Leukoc. Biol. 2007, 82, 752-762.

107. Drechsler, Y.; Dolganiuc, A.; Norkina, O.; Romics, L.; Li, W.; Kodys, K.; Bach, F.H.; Mandrekar, P.; Szabo, G. Heme oxygenase-1 mediates the anti-inflammatory effects of acute alcohol on IL-10 induction involving p38 MAPK activation in monocytes. J. Immunol. 2006, $177,2592-2600$.

108. Jung, M.E.; Ju,X.; Metzger, D.B.; Simpkins, J.W. Alcohol withdrawal-induced activation of protein kinase P38 targets neurons and a vulnerable age in an estrogen preventable manner. Alcohol Clin. Exp. Res. 2010, 34 Supplement.

109. Peart, J.N.; Gross, E.R.; Headrick, J.P.; Gross, G.J. Impaired p38 MAPK/HSP27 signaling underlies aging-related failure in opioid-mediated cardioprotection. J. Mol. Cell Cardiol. 2007, 42, 972-980.

110. Campos, C.B.; Bedard, P.A.; Linden, R. Requirement of p38 stress-activated MAP kinase for cell death in the developing retina depends on the stage of cell differentiation. Neurochem. Int. 2006, 49, 494-499.

111. Zepeda, R.C.; Barrera, I.; Castelan, F.; Soto-Cid, A.; Hernandez-Kelly, L.C.; Lopez-Bayghen, E.; Ortega, A. Glutamate-dependent transcriptional regulation in bergmann glia cells: Involvement of p38 MAP kinase. Neurochem. Res. 2008, 33, 1277-1285.

112. Galluzzi, L.; Blomgren, K.; Kroemer, G. Mitochondrial membrane permeabilization in neuronal injury. Nat. Rev. Neurosci. 2009, 10, 481-494.

113. Valles, S.L.; Borras, C.; Gambini, J.; Furriol, J.; Ortega, A.; Sastre, J.; Pallardo, F.V.; Vina, J. Oestradiol or genistein rescues neurons from amyloid beta-induced cell death by inhibiting activation of p38. Aging Cell 2008, 7, 112-118.

114. Wu, M.; Han, M.; Li, J.; Xu, X.; Li, T.; Que, L.; Ha, T.; Li, C.; Chen, Q.; Li, Y. 17beta-estradiol inhibits angiotensin II-induced cardiac myofibroblast differentiation. Eur. J. Pharmacol. 2009, 616, 155-159.

115. van Eickels, M.; Grohe, C.; Cleutjens, J.P.; Janssen, B.J.; Wellens, H.J.; Doevendans, P.A. 17beta-estradiol attenuates the development of pressure-overload hypertrophy. Circulation 2001, 104, 1419-1423. 
116. Wang, M.; Tsai, B.M.; Reiger, K.M.; Brown, J.W.; Meldrum, D.R. 17-beta-Estradiol decreases p38 MAPK-mediated myocardial inflammation and dysfunction following acute ischemia. $J$. Mol. Cell Cardiol. 2006, 40, 205-212.

117. Hsu, J.T.; Hsieh, Y.C.; Kan, W.H.; Chen, J.G.; Choudhry, M.A.; Schwacha, M.G.; Bland, K.I.; Chaudry, I.H. Role of p38 mitogen-activated protein kinase pathway in estrogen-mediated cardioprotection following trauma-hemorrhage. Am. J. Physiol. Heart Circ. Physiol. 2007, 292, H2982-H2987.

118. Miyoshi, N.; Oubrahim, H.; Chock, P.B.; Stadtman, E.R. Age-dependent cell death and the role of ATP in hydrogen peroxide-induced apoptosis and necrosis. Proc. Natl. Acad. Sci. USA 2006, 103, 1727-1731.

119. Wang, X.; Simpkins, J.W.; Dykens, J.A.; Cammarata, P.R. Oxidative damage to human lens epithelial cells in culture: estrogen protection of mitochondrial potential, ATP, and cell viability. Invest. Ophthalmol. Vis. Sci. 2003, 44, 2067-2075.

120. Mansouri, A.; Demeilliers, C.; Amsellem, S.; Pessayre, D.; Fromenty, B. Acute ethanol administration oxidatively damages and depletes mitochondrial dna in mouse liver, brain, heart, and skeletal muscles: Protective effects of antioxidants. J. Pharmacol. Exp. Ther. 2001, 298, 737-743.

121. Minana, J.B.; Gomez-Cambronero, L.; Lloret, A.; Pallardo, F.V.; Del Olmo, J.; Escudero, A.; Rodrigo, J.M.; Pelliin, A.; Vina, J.R.; Vina, J.; Sastre, J. Mitochondrial oxidative stress and CD95 ligand: A dual mechanism for hepatocyte apoptosis in chronic alcoholism. Hepatology 2002, 35, 1205-1214.

122. Siler-Marsiglio, K.I.; Pan, Q.; Paiva, M.; Madorsky, I.; Khurana, N.C.; Heaton, M.B. Mitochondrially targeted vitamin $\mathrm{E}$ and vitamin $\mathrm{E}$ mitigate ethanol-mediated effects on cerebellar granule cell antioxidant defense systems. Brain Res. 2005, 1052, 202-211.

123. Dolder, M.; Wendt, S.; Wallimann, T. Mitochondrial creatine kinase in contact sites: Interaction with porin and adenine nucleotide translocase, role in permeability transition and sensitivity to oxidative damage. Biol. Signals Recept. 2001, 10, 93-111.

124. Halestrap, A.P.; Brennerb, C. The adenine nucleotide translocase: A central component of the mitochondrial permeability transition pore and key player in cell death. Curr. Med. Chem. 2003, $10,1507-1525$.

125. Lipskaya, T.Y. Mitochondrial creatine kinase: Properties and function. Biochemistry (Mosc) 2001, 66, 1098-1111.

126. Stuart, R. Insertion of proteins into the inner membrane of mitochondria: The role of the Oxa1 complex. Biochim. Biophys. Acta 2002, 1592, 79-87.

127. Norenberg, M.D.; Rao, K.V. The mitochondrial permeability transition in neurologic disease. Neurochem. Int. 2007, 50, 983-997.

128. Kessova, I.G.; Cederbaum, A.I. Mitochondrial alterations in livers of Sod1-/- mice fed alcohol. Free Radical Biol. Med. 2007, 42, 1470-1480.

129. Vyssokikh, M.Y.; Brdiczka, D. The function of complexes between the outer mitochondrial membrane pore (VDAC) and the adenine nucleotide translocase in regulation of energy metabolism and apoptosis. Acta Biochim. Pol. 2003, 50, 389-404. 
130. Brustovetsky, N.; Brustovetsky, T.; Jemmerson, R.; Dubinsky, J.M. Calcium-induced cytochrome c release from CNS mitochondria is associated with the permeability transition and rupture of the outer membrane. J. Neurochem. 2002, 80, 207-218.

131. Fiskum, G.; Rosenthal, R.E.; Vereczki, V.; Martin, E.; Hoffman, G.E.; Chinopoulos, C.; Kowaltowski, A. Protection against ischemic brain injury by inhibition of mitochondrial oxidative stress. J. Bioenerg. Biomembr. 2004, 36, 347-352.

132. Halestrap, A.P. Calcium, mitochondria and reperfusion injury: A pore way to die. Biochem. Soc. Trans. 2006, 34, 232-237.

133. Reynolds, I.J. Mitochondrial membrane potential and the permeability transition in excitotoxicity. Ann. NY Acad. Sci. 1999, 893, 33-41.

134. Kratzer, U.; Schmidt, W.J. Caroverine inhibits the conditioned place aversion induced by naloxone-precipitated morphine withdrawal in rats. Neurosci. Lett. 2003, 349, 91-94.

135. Gatch, M.B. Ethanol withdrawal and hyperalgesia. Curr. Drug Abuse Rev. 2009, 2, 41-50.

136. Davila, J.C.; Olmos, L.; Legaz, I.; Medina, L.; Guirado, S.; Real, M.A. Dynamic patterns of colocalization of calbindin, parvalbumin and GABA in subpopulations of mouse basolateral amygdalar cells during development. J. Chem. Neuroanat. 2008, 35, 67-76.

137. Nowak, G.; Bakajsova, D.; Clifton, G.L. Protein kinase C-epsilon modulates mitochondrial function and active $\mathrm{Na}+$ transport after oxidant injury in renal cells. Am. J. Physiol. Renal. Physiol. 2004, 286, F307-F316.

138. Ishikawa, Y.; Kusaka, E.; Enokido, Y.; Ikeuchi, T.; Hatanaka, H. Regulation of Bax translocation through phosphorylation at Ser-70 of Bcl-2 by MAP kinase in NO-induced neuronal apoptosis. Mol. Cell Neurosci. 2003, 24, 451-459.

139. Pan, Z.; Bhat, M.B.; Nieminen, A.L.; Ma, J. Synergistic movements of $\mathrm{Ca}(2+)$ and Bax in cells undergoing apoptosis. J. Biol. Chem. 2001, 276, 32257-32263.

140. Semenova, M.M.; Maki-Hokkonen, A.M.; Cao, J.; Komarovski, V.; Forsberg, K.M.; Koistinaho, M.; Coffey, E.T.; Courtney, M.J. Rho mediates calcium-dependent activation of p38alpha and subsequent excitotoxic cell death. Nat. Neurosci. 2007, 10, 436-443.

141. Gomez-Lazaro, M.; Galindo, M.F.; Melero-Fernandez de Mera, R.M.; Fernandez-Gomez, F.J.; Concannon, C.G.; Segura, M.F.; Comella, J.X.; Prehn, J.H.; Jordan, J. Reactive oxygen species and p38 mitogen-activated protein kinase activate Bax to induce mitochondrial cytochrome c release and apoptosis in response to malonate. Mol. Pharmacol. 2007, 71, 736-743.

142. Mancuso, M.; Filosto, M.; Bosetti, F.; Ceravolo, R.; Rocchi, A.; Tognoni, G.; Manca, M.L.; Solaini, G.; Siciliano, G.; Murri, L. Decreased platelet cytochrome c oxidase activity is accompanied by increased blood lactate concentration during exercise in patients with Alzheimer disease. Exp. Neurol. 2003, 182, 421-426.

143. Brown, G.C.; Borutaite, V. Nitric oxide, cytochrome c and mitochondria. Biochem. Soc. Symp. 1999, 66, 17-25.

144. Jaatinen, P.; Riikonen, J.; Riihioja, P.; Kajander, O.; Hervonen, A. Interaction of aging and intermittent ethanol exposure on brain cytochrome c oxidase activity levels. Alcohol 2003, 29, 91-100. 
145. Jung, M.E.; Agarwal, R.; Simpkins, J.W. Ethanol withdrawal posttranslationally decreases the activity of cytochrome c oxidase in an estrogen reversible manner. Neurosci. Lett. 2007, 416, 160-164.

146. Vina, J.; Lloret, A.; Valles, S.L.; Borras, C.; Badia, M.C.; Pallardo, F.V.; Sastre, J.; Alonso, M.D. Effect of gender on mitochondrial toxicity of Alzheimer's Abeta peptide. Antioxid. Redox Signal. 2007, 9, 1677-1690.

147. Borras, C.; Sastre, J.; Garcia-Sala, D.; Lloret, A.; Pallardo, F.V.; Vina, J. Mitochondria from females exhibit higher antioxidant gene expression and lower oxidative damage than males. Free Radical Biol. Med. 2003, 34, 546-552.

148. Wang, J.; Green, P.S.; Simpkins, J.W. Estradiol protects against ATP depletion, mitochondrial membrane potential decline and the generation of reactive oxygen species induced by 3nitroproprionic acid in SK-N-SH human neuroblastoma cells. J. Neurochem. 2001, 77, 804-811.

149. Wang, X.; Dykens, J.A.; Perez, E.; Liu, R.; Yang, S.; Covey, D.F.; Simpkins, J.W. Neuroprotective effects of 17 beta-estradiol and nonfeminizing estrogens against $\mathrm{H} 2 \mathrm{O} 2$ toxicity in human neuroblastoma SK-N-SH cells. Mol. Pharmacol. 2006, 70, 395-404.

150. Prokai, L.; Simpkins, J.W. Structure-nongenomic neuroprotection relationship of estrogens and estrogen-derived compounds. Pharmacol. Ther. 2007, 114, 1-12.

151. Harms, C.; Lautenschlager, M.; Bergk, A.; Katchanov, J.; Freyer, D.; Kapinya, K.; Herwig, U.; Megow, D.; Dirnagl, U.; Weber, J.R.; Hortnagl, H. Differential mechanisms of neuroprotection by 17 beta-estradiol in apoptotic versus necrotic neurodegeneration. J. Neurosci. 2001, 21, 2600-2609.

152. Chen, J.Q.; Yager, J.D. Estrogen's effects on mitochondrial gene expression: mechanisms and potential contributions to estrogen carcinogenesis. Ann. NY Acad. Sci. 2004, 1028, 258-272.

153. Lee, C.S.; Kim, Y.J.; Ko, H.H.; Han, E.S. Synergistic effects of hydrogen peroxide and ethanol on cell viability loss in PC12 cells by increase in mitochondrial permeability transition. Biochem. Pharmacol. 2005, 70, 317-325.

154. Sokol, R.J.; Dahl, R.; Devereaux, M.W.; Yerushalmi, B.; Kobak, G.E.; Gumpricht, E. Human hepatic mitochondria generate reactive oxygen species and undergo the permeability transition in response to hydrophobic bile acids. J. Pediatr. Gastroenterol. Nutr. 2005, 41, 235-243.

155. Dhandapani, K.M.; Brann, D.W. Protective effects of estrogen and selective estrogen receptor modulators in the brain. Biol. Reprod. 2002, 67, 1379-1385.

156. Ha, E.J.; Smith, A.M. Plasma selenium and plasma and erythrocyte glutathione peroxidase activity increase with estrogen during the menstrual cycle. J. Am. Coll. Nutr. 2003, 22, 43-51.

157. Lapointe, J.; Kimmins, S.; Maclaren, L.A.; Bilodeau, J.F. Estrogen selectively up-regulates the phospholipid hydroperoxide glutathione peroxidase in the oviducts. Endocrinology 2005, 146, 2583-2592.

158. Nilsen, J.; Diaz Brinton, R. Mechanism of estrogen-mediated neuroprotection: regulation of mitochondrial calcium and Bcl-2 expression. Proc. Natl. Acad. Sci. USA 2003, 100, 2842-2847.

159. Culberson, J.W. Alcohol use in the elderly: Beyond the CAGE. Part 1 of 2: prevalence and patterns of problem drinking. Geriatrics 2006, 61, 23-27.

160. Culberson, J.W. Alcohol use in the elderly: beyond the CAGE. Part 2: Screening instruments and treatment strategies. Geriatrics 2006, 61, 20-26. 
161. Meier, P.; Seitz, H.K. Age, alcohol metabolism and liver disease. Curr. Opin. Clin. Nutr. Metab. Care 2008, 11, 21-26.

162. Tarter, R.E.; Edwards, K.L. Multifactorial etiology of neuropsychological impairment in alcoholics. Alcohol Clin. Exp. Res. 1986, 10, 128-135.

163. Riihioja, P.; Jaatinen, P.; Haapalinna, A.; Kiianmaa, K.; Hervonen, A. Effects of ageing and intermittent ethanol exposure on rat locus coeruleus and ethanol-withdrawal symptoms. Alcohol Alcohol. 1999, 34, 706-717.

164. Cocuzza, M.; Athayde, K.S.; Agarwal, A.; Sharma, R.; Pagani, R.; Lucon, A.M.; Srougi, M.; Hallak, J. Age-related increase of reactive oxygen species in neat semen in healthy fertile men. Urology 2008, 71, 490-494.

165. Judge, S.; Jang, Y.M.; Smith, A.; Hagen, T.; Leeuwenburgh, C. Age-associated increases in oxidative stress and antioxidant enzyme activities in cardiac interfibrillar mitochondria: implications for the mitochondrial theory of aging. FASEB J. 2005, 19, 419-421.

166. Mehta, R.; Shangari, N.; O'Brien, P.J. Preventing cell death induced by carbonyl stress, oxidative stress or mitochondrial toxins with vitamin B anti-AGE agents. Mol. Nutr. Food Res. 2008, 52, 379-385.

167. Abdel, S.E.; Abdel-Meguid, I.; Korraa, S. Markers of oxidative stress and aging in Duchene muscular dystrophy patients and the possible ameliorating effect of He:Ne laser. Acta Myol. 2007, 26, 14-21.

168. Navarro, A.; Lopez-Cepero, J.M.; Bandez, M.J.; Sanchez-Pino, M.J.; Gomez, C.; Cadenas, E.; Boveris, A. Hippocampal mitochondrial dysfunction in rat aging. Am. J. Physiol. Regul. Integr. Comp. Physiol. 2008, 294, R501-R509.

169. Opii, W.O.; Joshi, G.; Head, E.; Milgram, N.W.; Muggenburg, B.A.; Klein, J.B.; Pierce, W.M.; Cotman, C.W.; Butterfield, D.A. Proteomic identification of brain proteins in the canine model of human aging following a long-term treatment with antioxidants and a program of behavioral enrichment: relevance to Alzheimer's disease. Neurobiol. Aging 2008, 29, 51-70.

170. Safciuc, F.; Constantin, A.; Manea, A.; Nicolae, M.; Popov, D.; Raicu, M.; Alexandru, D.; Constantinescu, E. Advanced glycation end products, oxidative stress and metalloproteinases are altered in the cerebral microvasculature during aging. Curr. Neurovasc. Res. 2007, 4, 228-234.

171. Bugalho, P.; Viana-Baptista, M.; Jordao, C.; Secca, M.F.; Ferro, J.M. Age-related white matter lesions are associated with reduction of the apparent diffusion coefficient in the cerebellum. Eur. J. Neurol. 2007, 14, 1063-1066.

172. Giusto, N.M.; Salvador, G.A.; Castagnet, P.I.; Pasquare, S.J.; Ilincheta de Boschero, M.G. Ageassociated changes in central nervous system glycerolipid composition and metabolism. Neurochem. Res. 2002, 27, 1513-1523.

173. Wojnar, M.; Wasilewski, D.; Zmigrodzka, I.; Grobel, I. Age-related differences in the course of alcohol withdrawal in hospitalized patients. Alcohol Alcohol. 2001, 36, 577-583.

174. Davies, B.T.; Bowen, C.K. Total body water and peak alcohol concentration: A comparative study of young, middle-age, and older females. Alcohol Clin. Exp. Res. 1999, 23, 969-975.

175. Young, C.; Klocke, B.J.; Tenkova, T.; Choi, J.; Labruyere, J.; Qin, Y.Q.; Holtzman, D.M.; Roth, K.A.; Olney, J.W. Ethanol-induced neuronal apoptosis in vivo requires BAX in the developing mouse brain. Cell Death Differ. 2003, 10, 1148-1155. 
176. Kim, Y.C.; Kim, S.Y.; Sohn, Y.R. Effect of age increase on metabolism and toxicity of ethanol in female rats. Life Sci. 2003, 74, 509-519.

177. Williamson, D.; Gallagher, P.; Harber, M.; Hollon, C.; Trappe, S. Mitogen-activated protein kinase (MAPK) pathway activation: Effects of age and acute exercise on human skeletal muscle. J. Physiol. 2003, 547, 977-987.

178. Kelleher, I.; Garwood, C.; Hanger, D.P.; Anderton, B.H.; Noble, W. Kinase activities increase during the development of tauopathy in htau mice. J. Neurochem. 2007, 103, 2256-2267.

179. Hensley, K.; Floyd, R.A.; Zheng, N.Y.; Nael, R.; Robinson, K.A.; Nguyen, X.; Pye, Q.N.; Stewart, C.A.; Geddes, J.; Markesbery, W.R.; Patel, E.; Johnson, G.V.; Bing, G. p38 kinase is activated in the Alzheimer's disease brain. J. Neurochem. 1999, 72, 2053-2058.

180. Vereker, E.; O'Donnell, E.; Lynch, M.A. The inhibitory effect of interleukin-1beta on long-term potentiation is coupled with increased activity of stress-activated protein kinases. J. Neurosci. 2000, 20, 6811-6819.

181. Watanabe, M. Molecular mechanisms governing competitive synaptic wiring in cerebellar Purkinje cells. Tohoku J. Exp. Med. 2008, 214, 175-190.

182. Becker, E.B.; Oliver, P.L.; Glitsch, M.D.; Banks, G.T.; Achilli, F.; Hardy, A.; Nolan, P.M.; Fisher, E.M.; Davies, K.E. A point mutation in TRPC3 causes abnormal Purkinje cell development and cerebellar ataxia in moonwalker mice. Proc. Natl. Acad. Sci. USA 2009, 106, 6706-6711.

183. Levin, S.I.; Khaliq, Z.M.; Aman, T.K.; Grieco, T.M.; Kearney, J.A.; Raman, I.M.; Meisler, M.H. Impaired motor function in mice with cell-specific knockout of sodium channel Scn8a (NaV1.6) in cerebellar purkinje neurons and granule cells. J. Neurophysiol. 2006, 96, 785-793.

184. Carta, M.; Mameli, M.; Valenzuela, C.F. Alcohol potently modulates climbing fiber-->Purkinje neuron synapses: role of metabotropic glutamate receptors. J. Neurosci. 2006, 26, 1906-1912.

185. Markowska, A.L. Sex dimorphisms in the rate of age-related decline in spatial memory: Relevance to alterations in the estrous cycle. J. Neurosci. 1999, 19, 8122-8133.

186. Kok, E.; Haikonen, S.; Luoto, T.; Huhtala, H.; Goebeler, S.; Haapasalo, H.; Karhunen, P.J. Apolipoprotein E-dependent accumulation of Alzheimer disease-related lesions begins in middle age. Ann. Neurol. 2009, 65, 650-657.

187. Finch, C.E. The neurobiology of middle-age has arrived. Neurobiol. Aging 2009, 30, 515-520, discussion 530-533.

188. Li, L.; Shou, Y.; Borowitz, J.L.; Isom, G.E. Reactive oxygen species mediate pyridostigmineinduced neuronal apoptosis: Involvement of muscarinic and NMDA receptors. Toxicol. Appl. Pharmacol. 2001, 177, 17-25.

189. Guarnieri, C.; Muscari, C.; Caldarera, C.M. Mitochondrial production of oxygen free radicals in the heart muscle during the life span of the rat: Peak at middle age. EXS 1992, 62, 73-77.

190. Joseph, J.A.; Kochman, K.; Roth, G.S. Reduction of motor behavioural deficits in senescence via chronic prolactin or estrogen administration: time course and putative mechanisms of action. Brain Res. 1989, 505, 195-202.

191. Rapp, S.R.; Espeland, M.A.; Shumaker, S.A.; Henderson, V.W.; Brunner, R.L.; Manson, J.E.; Gass, M.L.; Stefanick, M.L.; Lane, D.S.; Hays, J.; Johnson, K.C.; Coker, L.H.; Dailey, M.; Bowen, D. Effect of estrogen plus progestin on global cognitive function in postmenopausal 
women: the Women's Health Initiative Memory Study: A randomized controlled trial. JAMA 2003, 289, 2663-2672.

192. Ziegler, D.R.; Gallagher, M. Spatial memory in middle-aged female rats: assessment of estrogen replacement after ovariectomy. Brain Res. 2005, 1052, 163-173.

193. Gibbs, R.B. Long-term treatment with estrogen and progesterone enhances acquisition of a spatial memory task by ovariectomized aged rats. Neurobiol. Aging 2000, 21, 107-116.

194. Lacreuse, A.; Wilson, M.E.; Herndon, J.G. Estradiol, but not raloxifene, improves aspects of spatial working memory in aged ovariectomized rhesus monkeys. Neurobiol. Aging 2002, 23, 589-600.

195. Zandi, P.P.; Carlson, M.C.; Plassman, B.L.; Welsh-Bohmer, K.A.; Mayer, L.S.; Steffens, D.C.; Breitner, J.C. Hormone replacement therapy and incidence of Alzheimer disease in older women: The Cache County Study. JAMA 2002, 288, 2123-2129.

Sample Availability: Samples of the compounds are available from the authors.

(C) 2010 by the authors; licensee MDPI, Basel, Switzerland. This article is an Open Access article distributed under the terms and conditions of the Creative Commons Attribution license (http://creativecommons.org/licenses/by/3.0/). 